\title{
Optimização Energética em Novos Ascensores
}

\section{EnquadRAMENTO}

De acordo com um estudo da S.A.F.E - "Agência Suíça para a Utilização Eficiente da Energia", realizado em 2005, os ascensores podem representar uma parte significativa do consumo de energia num edifício (o consumo energético de um ascensor poder representar em média $5 \%$ do consumo total de energia de um edifício de escritórios). Na Suíça estima-se que o somatório do consumo de energia dos cerca de 150.000 ascensores instalados represente cerca de 0,5\% do total de $280 \mathrm{GWh}$ de consumo energético do país.

A redução do consumo de energia nos edifícios poderá ser obtida através da melhoria das características construtivas, reduzindo dessa forma as necessidades energéticas, através de medidas de gestão da procura, no sentido de reduzir os consumos na utilização e através do recurso a equipamentos energeticamente mais eficientes.

No preâmbulo da Directiva 2005/32/CE de 06 de Julho de 2005 - "EuP - Energy Using Products" (Requisitos de concepção ecológica dos produtos que consomem energia) ${ }^{1}$ refere-se que "a melhoria da eficiência energética - de que uma das opções disponíveis consiste na utilização final mais eficiente da electricidade - é considerada um contributo importante para a realização dos objectivos de redução das emissões de gases com efeito de estufa na Comunidade." Daí que seja importante estudar também a optimização energética em novos ascensores.

\section{Desenvolvimento do modelo em Matlab-Simulink}

De acordo com a Directiva 2005/32/CE de 06 de Julho acima referida, "deverá actuar-se na fase de concepção do produto, já que é aí que a poluição originada no seu ciclo de vida é determinada e que a maior parte dos custos surgem".
Para o estudo de optimização energética na fase de desenvolvimento de novos ascensores desenvolveu-se um modelo de simulação que permitiu analisar diversos cenários e apresentar soluções a ter em conta na fase de definição de um novo ascensor.

\subsection{FunCIONAMENTO DO SISTEMA DE ACCIONAMENTO ELECTROMECÂNICO E A SUA MODELIZAÇÃo}

Segundo Palma (2008) as partes móveis dos accionamentos envolvem quase sempre fenómenos complexos, quer pela multiplicidade dos seus detalhes, quer pela sua própria natureza, muitas vezes, não linear.

Contudo, como o objectivo da modelação é a utilização em sistemas de controlo onde intervêm diversos outros subsistemas, com destaque para os eléctricos, os electrónicos e os mecânicos, procuram-se modelos matemáticos tão simples quanto possível para cada um deles.

Para muitos dos sistemas electromecânicos que se pretende modelizar pode-se considerar simplificadamente a seguinte equação de comportamento dinâmico, baseada na lei fundamental da dinâmica para um sistema rotativo:

$T_{m}-T_{r}=J \frac{d w}{d t}$

Onde $T_{m}$ representa o binário motor (expresso em $\mathrm{Nm}$ ), $T_{\mathrm{r}} \mathrm{o}$ binário resistente (expresso em $\mathrm{Nm}$ ), J o momento de inércia do sistema (expresso em $\mathrm{kgm}^{2}$ ) e $\frac{d w}{d t}$ a aceleração angular (rad.s- $\left.{ }^{2}\right)$.

O momento de inércia será calculado a partir de:

$$
\begin{aligned}
& \text { T. } \omega=F \cdot v \Leftrightarrow J \frac{d \omega}{d t} \omega=m \cdot a \cdot v \Leftrightarrow J \frac{d \omega}{d t} \omega=m \cdot \frac{d \omega}{d t} r \cdot \omega \cdot r \\
& \Leftrightarrow J=m \cdot r^{2}
\end{aligned}
$$

\footnotetext{
${ }^{1}$ Esta directiva cria um quadro de definição dos requisitos comunitários de concepção ecológica dos produtos consumidores de energia com o objectivo de garantir a livre circulação destes produtos nos mercado interno. Prevê ainda a definição de requisitos a observar pelos produtos consumidores de energia abrangidos por medidas de execução, com vista à sua colocação no mercado e/ou colocação em serviço. Contribui para o desenvolvimento sustentável, na medida em que aumenta a eficiência energética e o nível de proteç̧ão do ambiente, e permite ao mesmo tempo aumentar a segurança do fornecimento de energia
} 
Onde $\mathrm{m}$ representa a massa suportada pela roda de tracção e r o raio da roda de tracção da máquina.

A potência mecânica do sistema será obtida a partir de:

$P=F \cdot v=T \cdot \omega \Rightarrow T=\frac{F \cdot v}{\omega}$

Sendo a velocidade linear v, dada por:

$v=\omega \cdot r$

Como sob o ponto de vista electrotécnico todo o sistema de accionamento electromecânico está subordinado ao motor eléctrico ter-se-á de reduzir as diferentes grandezas mecânicas envolvidas ao eixo motor. Nessa redução utilizase o Princípio da Conservação da Energia.

A energia cinética é dada por:

$E C=\frac{1}{2} J \omega^{2}$

Então para o todo o sistema será válida a seguinte relação:

$$
E c_{1}=E c_{2} \Rightarrow \frac{1}{2} J_{1} \omega_{1}^{2}=\frac{1}{2} J_{2} \omega_{2}^{2} \Leftrightarrow J_{1} \omega_{1}^{2}=J_{2} \omega_{2}^{2}
$$

As equações [1] a [6] foram então transpostas para o modelo em Matlab-Simulink.

Apresenta-se na figura 1 o modelo de base do ascensor eléctrico com roda de aderência e máquina com redutor.
Ainda segundo Palma (2008), um sistema de accionamento electromecânico de velocidade variável, que permite o ajuste de velocidade, de posição ou de binário, dentro de certas gamas de variação, é constituído por diversos componentes:

1. Fonte de energia eléctrica;

2. Conversor estático de potência;

3. Máquina eléctrica, incluindo a transmissão;

4. Sistema mecânico movido, ou carga;

5. Órgãos electrónicos de controlo e de comando do conversor.

\subsection{O MOdELO DO ASCENSOR EM MATLAB-SIMULINK}

Na concepção do modelo simulink separou-se cada um dos componentes do sistema, eléctrico e mecânico (elevador), para uma maior facilidade de parametrização e interpretação de resultados, conforme as figuras 2 e 3 . Foram ainda concentrados todos os outputs das grandezas mecânicas consideradas, num mesmo bloco (caixa redutora), que simula o acoplamento mecânico com o motor eléctrico. As grandezas eléctricas de monitorização são retiradas do próprio bloco variador/motor (AC2).

Desta forma, o modelo foi dividido em três blocos principais - Bloco Mecânico, Bloco Eléctrico e Blocos de medições de grandezas eléctricas e mecânicas -, que por sua vez se subdividem em outros blocos secundários, conforme a seguir se descreve.

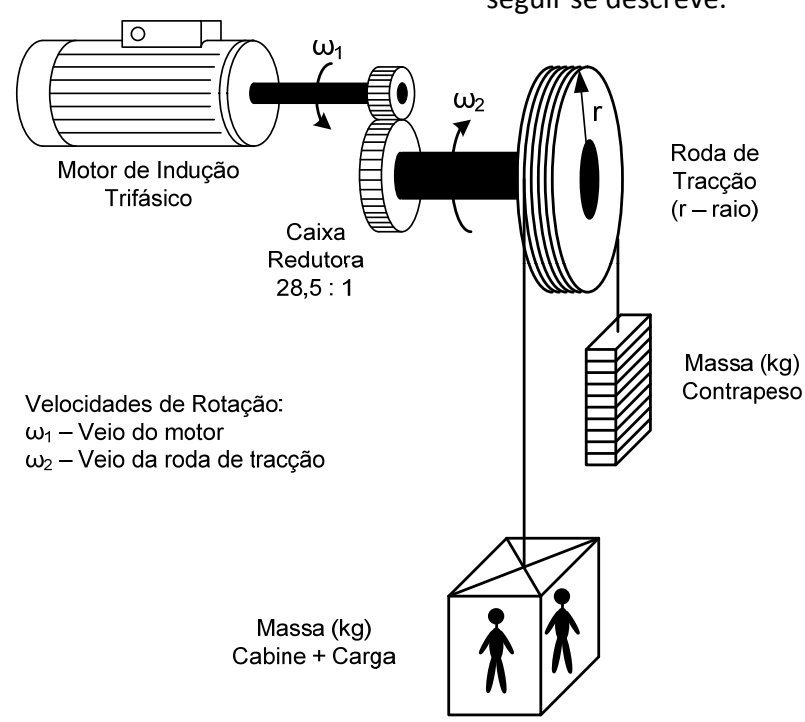

Figura 1 - Modelo de base do ascensor eléctrico com roda de aderência e máquina com redutor 


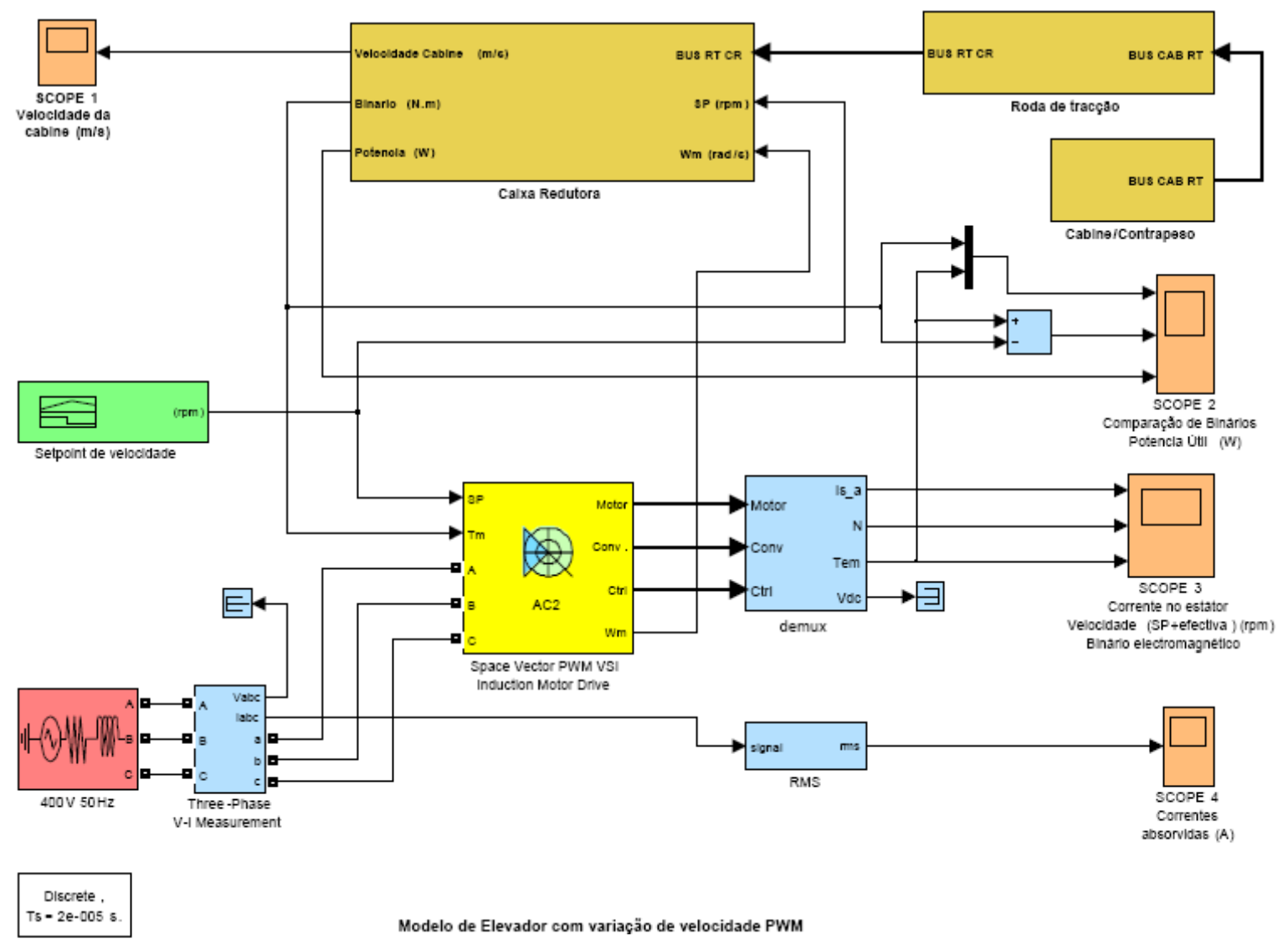

Figura 2 - Diagrama geral de blocos do ascensor com variação de velocidade PWM

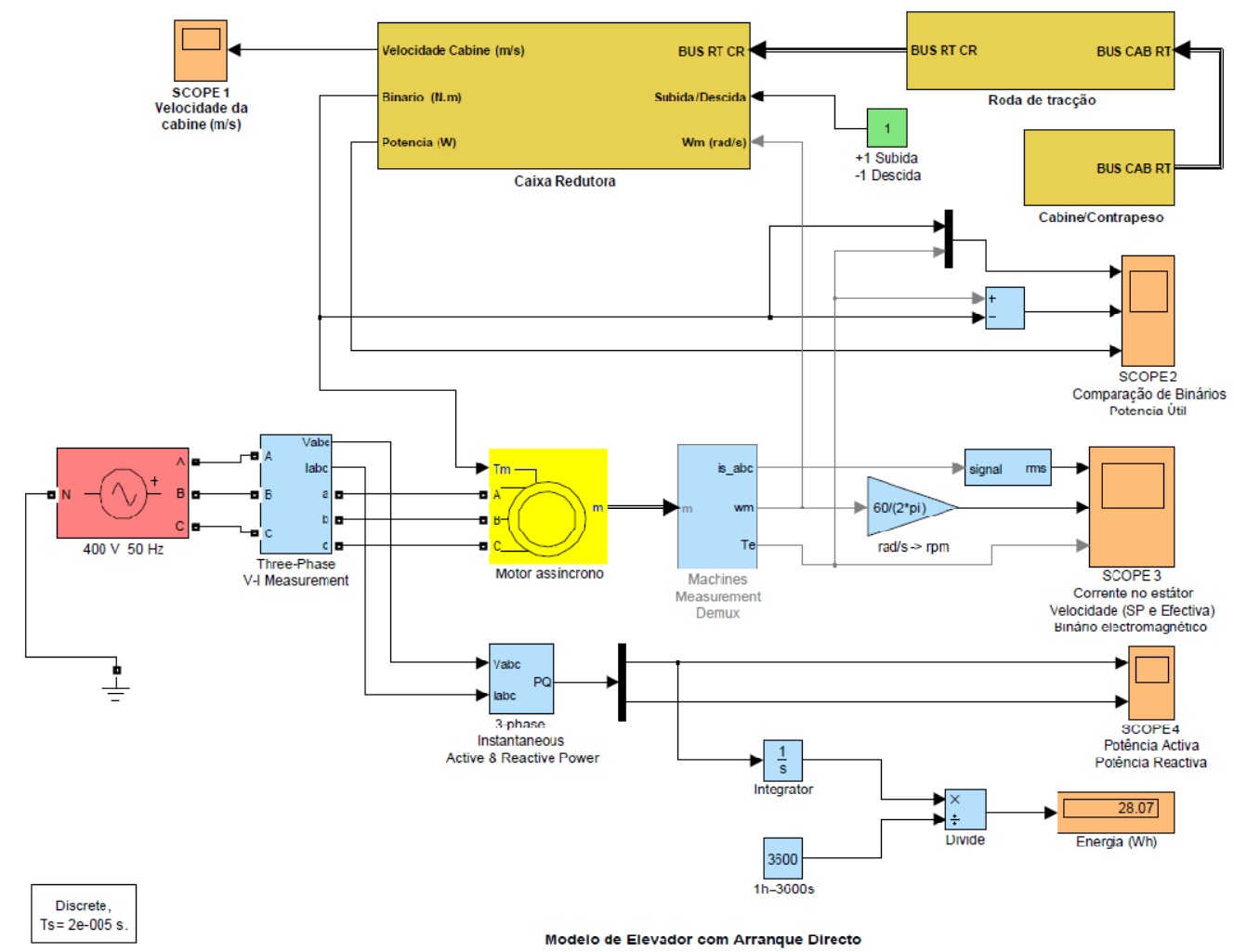

Figura 3 - Diagrama geral de blocos do ascensor - Arranque directo 


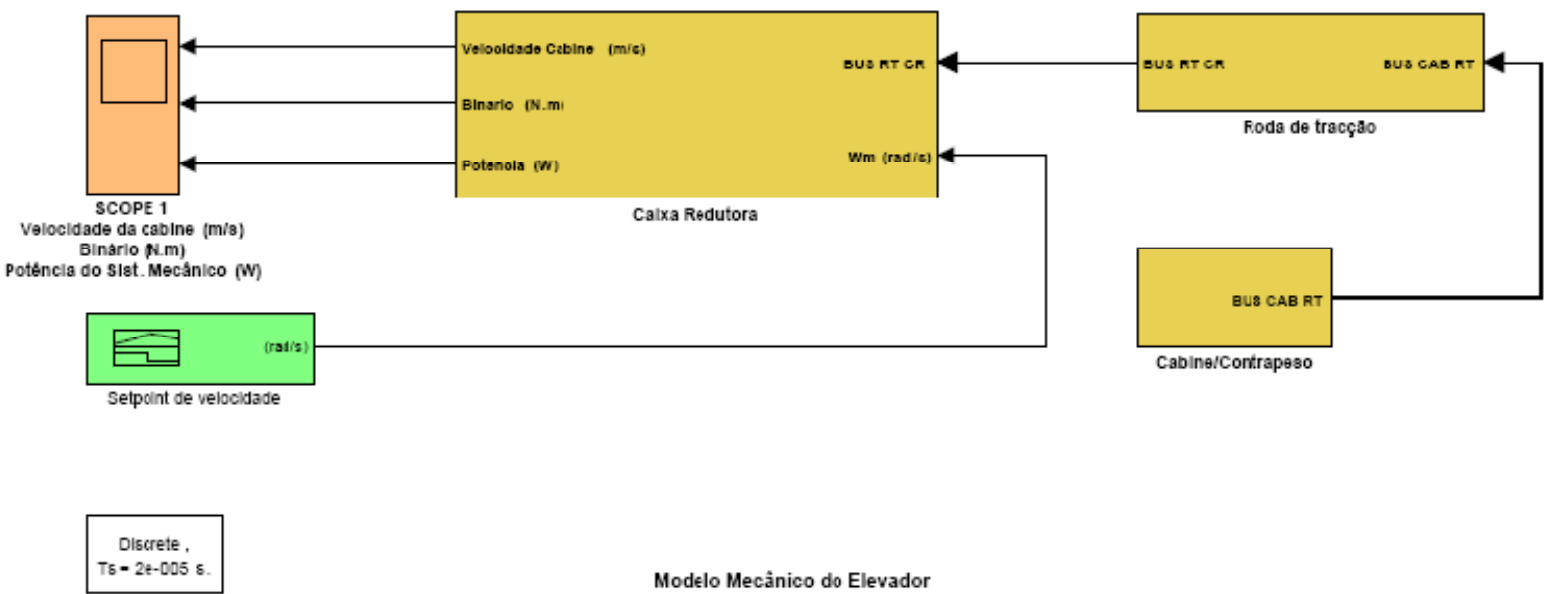

Figura 4 - Diagrama geral de blocos do ascensor - Modelo mecânico

\subsubsection{BLOCO MECÂNICO (ASCENSOR)}

O bloco mecânico foi dividido em três sub-blocos, correspondentes a cada um dos componentes mecânicos do sistema:

1. A cabine do ascensor;

2. A roda de tracção;

3. A caixa redutora.

\subsubsection{CABINE DO ASCENSOR}

A cabina do ascensor pode ser modelizada a partir do seguinte conjunto de sub-blocos:

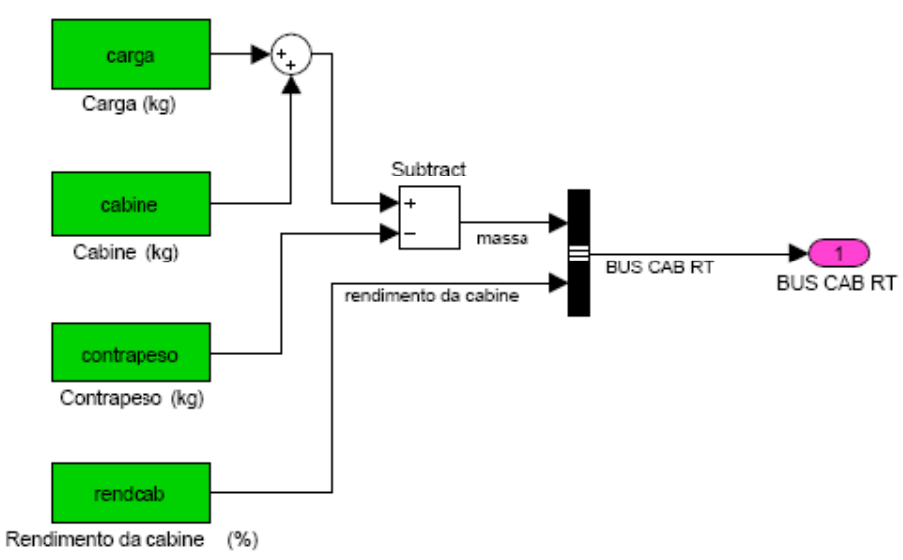

Figura 5 - Diagrama de blocos Simulink da cabine
$\mathrm{Na}$ janela de parametrização da cabine do ascensor são introduzidas as massas do conjunto cabine/contrapeso. 0 bloco simulink faz a soma das massas da carga e da cabine e finalmente subtrai a massa do contrapeso ${ }^{2}$. Se o resultado for positivo o sistema vai criar um binário resistente positivo na subida da cabine e negativo na descida da mesma, conforme tabela 1 . Considerou-se ainda o rendimento da cabine, que representa as perdas por atrito das roçadeiras da cabina nas guias, eventuais oscilações dos cabos, etc.

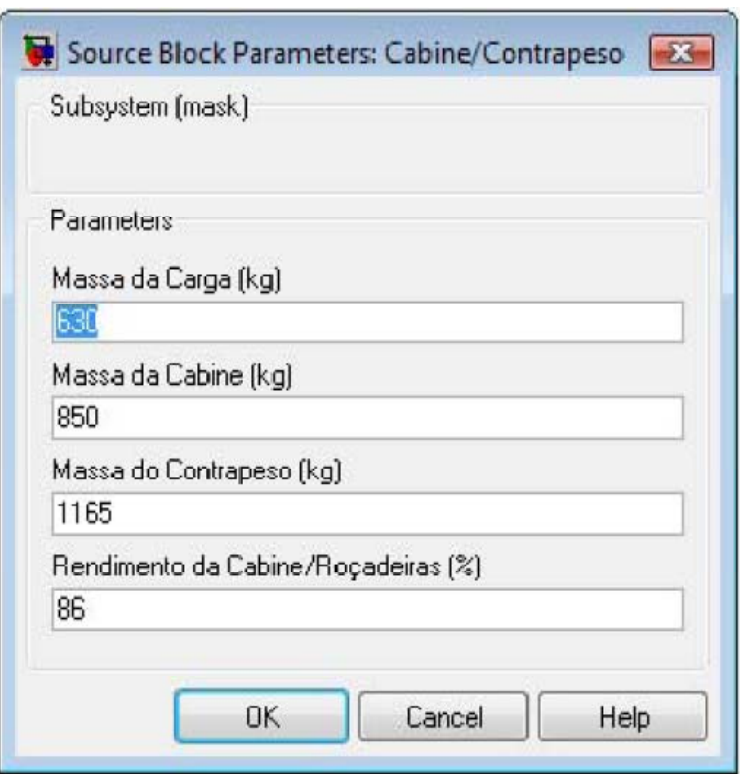

Figura 6 - Janela de parametrização da cabine/contrapeso

${ }^{2}$ É prática na indústria de ascensores que o contrapeso seja dimensionado para contrabalançar a massa da cabina $+50 \%$ da carga nominal da cabina. Assim, para uma cabina com uma carga útil de $630 \mathrm{~kg}$ e um peso próprio de $850 \mathrm{~kg}$, o contrapeso terá de ter uma massa de $1165 \mathrm{~kg}$. Procurar-se-á através de uma análise de cenários verificar se esta é a solução óptima em termos de consumo energético. 
Tabela 1 - Sentido do binário resistente em função do movimento da cabine e das massas

\begin{tabular}{|c|c|c|}
\hline & \multicolumn{3}{|c|}{ Binário Resistente } \\
\hline Movimento da Cabine & \multicolumn{2}{|c|}{ Massas $(\mathrm{kg})$} \\
\hline & $($ Carga+Cabine $)>$ Contrapeso & (Carga+Cabine) < Contrapeso \\
\hline Subida & positivo & negativo \\
\hline Descida & negativo & positivo \\
\hline
\end{tabular}

O output deste bloco será a massa resultante do sistema cabine/contrapeso responsável pela força vertical do sistema (peso), que poderá ser positiva ou negativa e será um dos inputs do bloco da roda de traç̧ão.

\subsubsection{RodA DE TRACÇÃo}

A roda de tracção da máquina elevadora pode ser modelizada a partir do conjunto de sub-blocos indicados na figura 7.

$\mathrm{Na}$ janela de parametrização, são introduzidos os dados relativos à roda de tracção, nomeadamente o momento de inércia, o rendimento e o raio da roda de traç̧ão.
Como já foi dito anteriormente, outro dos inputs é a massa resultante do sistema cabine/contrapeso, responsável por parte do momento de inércia do sistema que influenciará o binário transitório (arranques/paragens) e pelo binário permanente, quando a cabina atinge a velocidade nominal. No bloco simulink da roda de tracção será calculado o binário resistente permanente referido ao seu eixo, bem como o momento de inércia resultante da carga total do sistema cabine/contrapeso, sendo este referido também ao mesmo eixo. Estas duas grandezas associadas ao rendimento da roda de tracção e ao seu raio, integrarão um bus de dados de output, que será um dos inputs do bloco da caixa redutora.

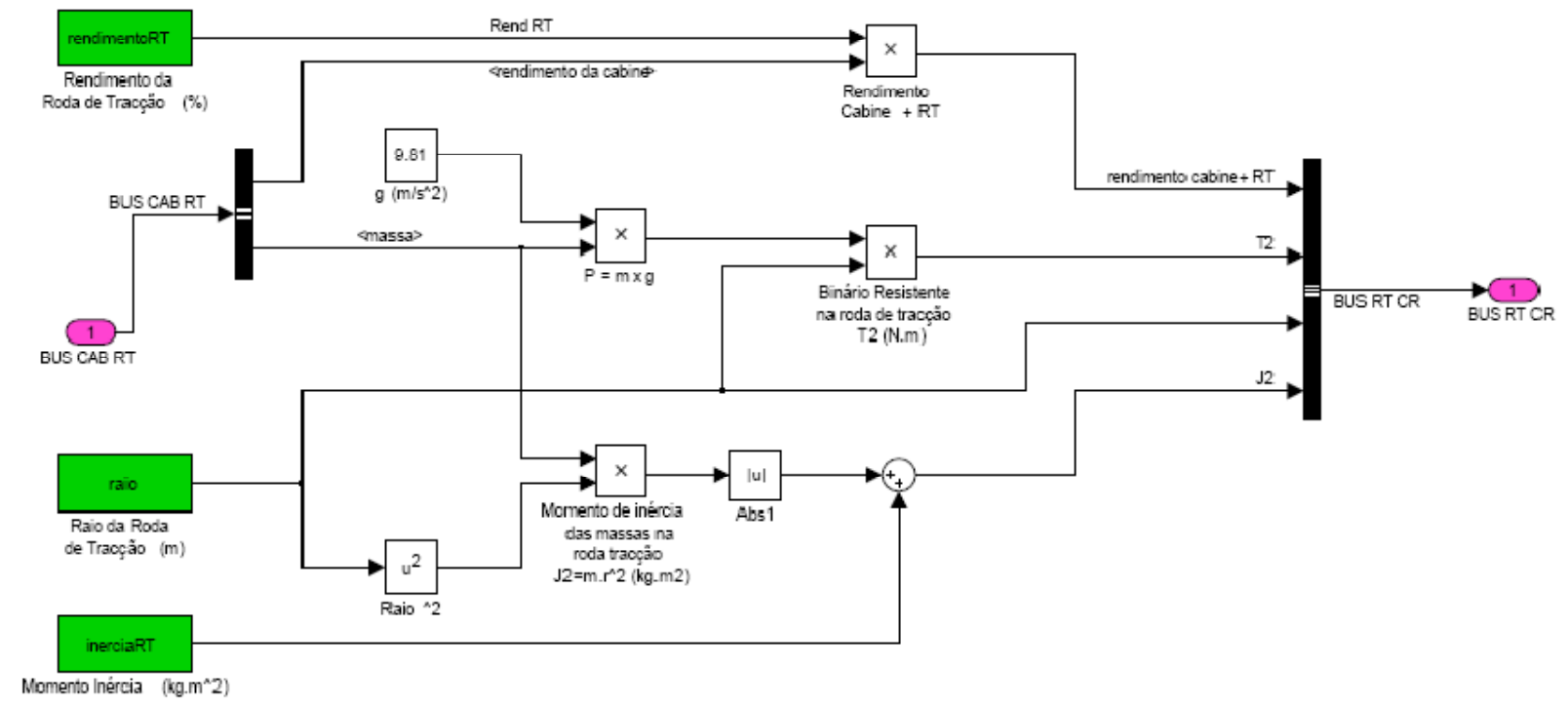

Figura 7 - Diagrama de blocos Simulink da roda de tracção 


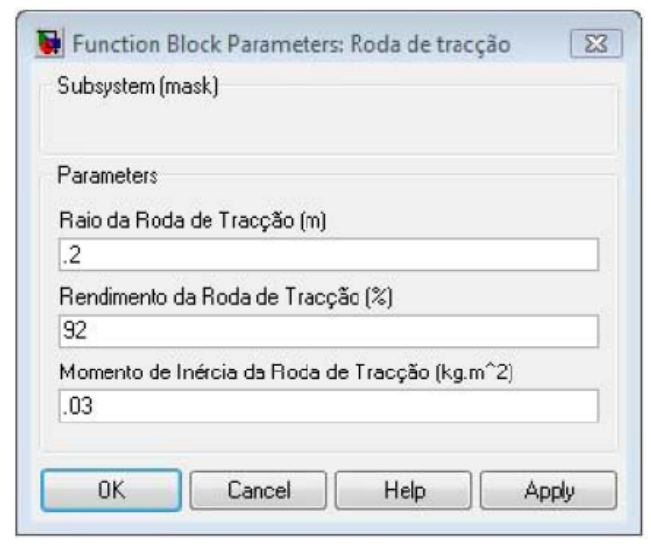

Figura 8 - Janela de parametrização da roda de tracção

\subsubsection{CAIXA Redutora}

A caixa redutora da máquina elevadora pode ser modelizada a partir do conjunto de sub-blocos, indicados na figura 9 , para a situação de variação de velocidade e arranque directo.

Na modelização do arranque directo, o motor roda sempre no mesmo sentido de tal forma que para distinguir a subida da descida da cabine, foi necessário implementar algumas modificações para que o bloco identificasse ambas as situações, conforme indicado na figura 10.

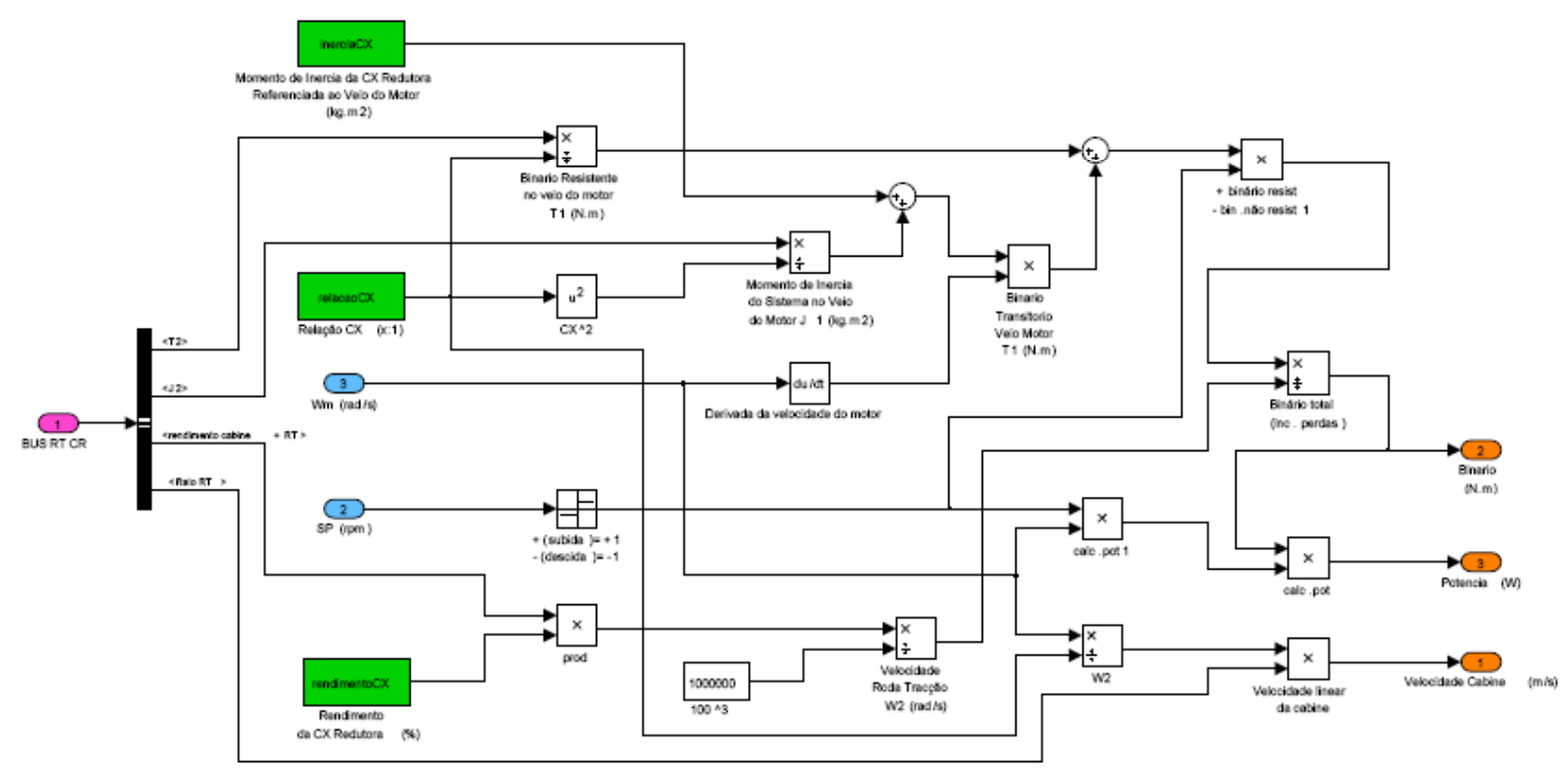

Figura 9 - Diagrama de blocos Simulink da caixa redutora com variador de velocidade

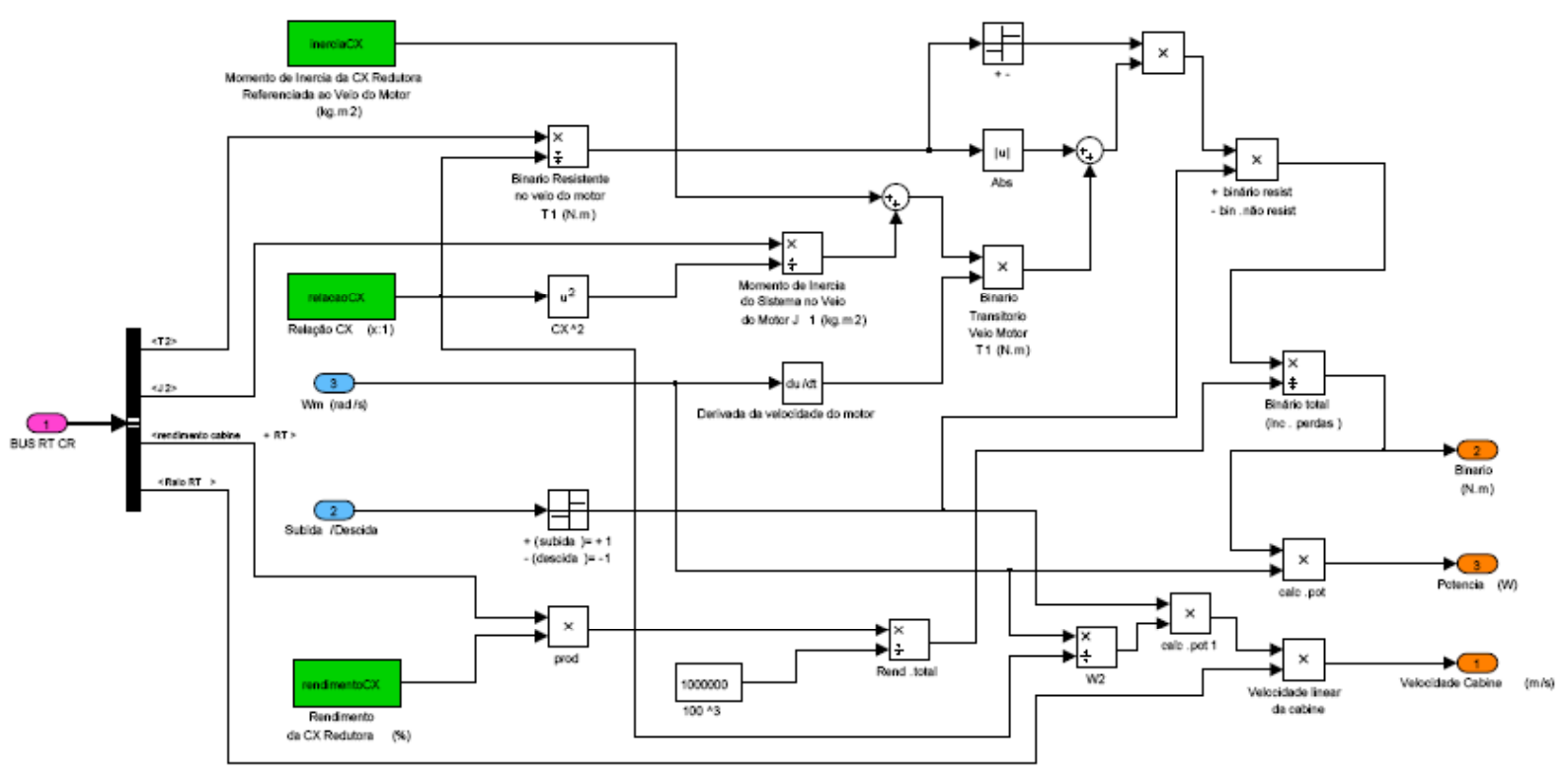

Figura 10 - Diagrama de blocos Simulink da caixa redutora para o arranque directo 
O input de dados do bloco simulink da caixa redutora dividese pelo bus de dados proveniente da roda de tracção, pelos parâmetros introduzidos pelo utilizador, tais como o momento de inércia, rendimento e a relação da caixa redutora e finalmente pela velocidade de rotação ( $\mathrm{rad} / \mathrm{s})$ no veio do motor (rotação efectiva do motor) e pelo Setpoint de velocidade. A velocidade de rotação vai permitir o cálculo do binário transitório, bem como a potência solicitada e a velocidade linear da cabine.

De referir ainda que o Setpoint de velocidade neste bloco tem uma actuação indirecta, permitindo unicamente definir o sentido do binário resistente. Os outputs deste bloco são o binário resistente, referido ao veio do motor, que será o input mecânico do motor de indução, que por sua vez vai gerar a velocidade de rotação que serve de input ao mesmo bloco. São ainda outputs, a potência solicitada pelo sistema e a velocidade linear da cabine, sendo estas duas grandezas só para monitorização, não tendo por isso qualquer interferência com o sistema.

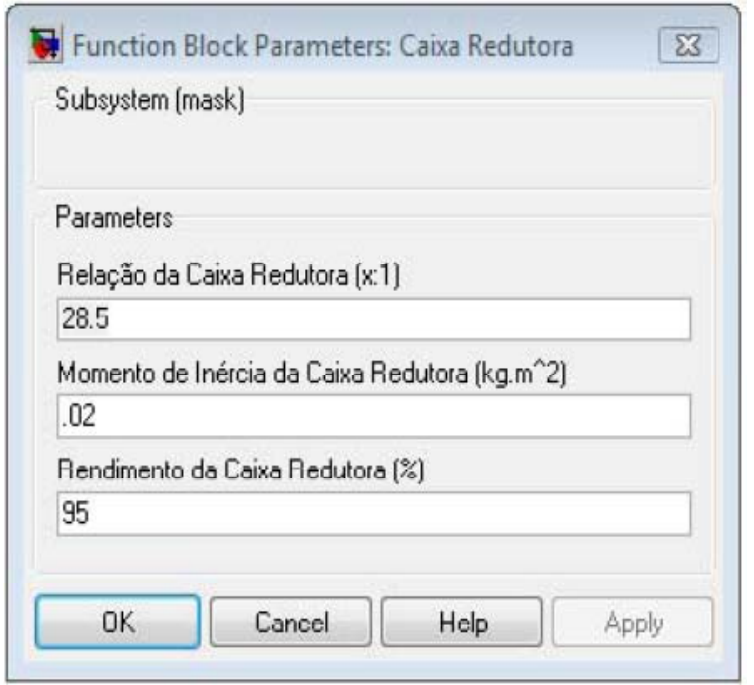

Figura 11 - Janela de parametrização da caixa redutora

\subsubsection{SETPOINT DE VELOCIDADE DO MOTOR}

Através desta função define-se a curva de aceleração, desaceleração e velocidade nominal da carga, quer à subida quer à descida. Pretende-se simular uma viagem completa da cabina ${ }^{3}$.

O Tempo de arranque/paragem foi definido com o sendo de um segundo.

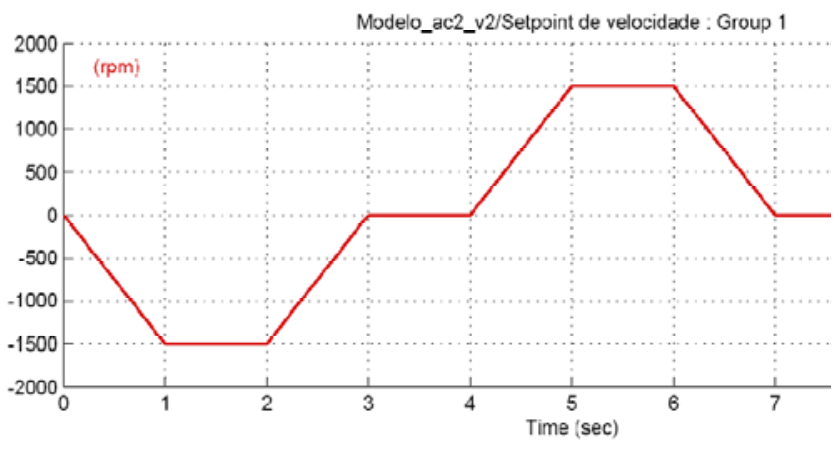

Figura 12 - Setpoint de velocidade do motor com variação de velocidade

\subsubsection{BLOCO ELÉCTRICO}

Este bloco é constituído por dois sub-blocos:

\subsubsection{FONTE DE ALIMENTAÇÃO}

Este bloco estabelece as condições da rede eléctrica (400V AC $50 \mathrm{~Hz}$ ), conforme os parâmetros introduzidos na janela de parametrização.

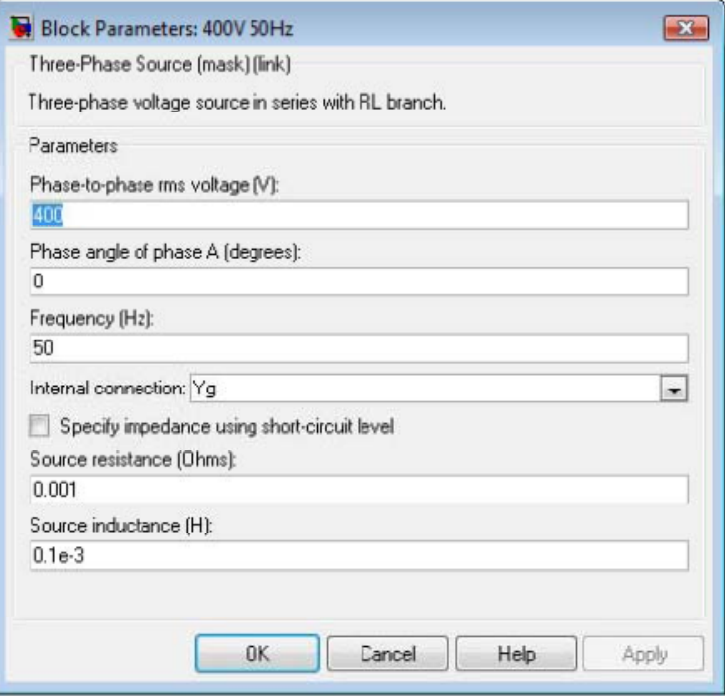

Figura 13 - Janela de parametrização da fonte de alimentação (input de dados pelo utilizador)

\footnotetext{
${ }^{3}$ Viagem com a cabina em vazio, em sentido descendente e ascendente, vencendo todo o curso, isto é, a cabina deve ser movimentada entre os pisos extremos do edifício.
} 


\subsubsection{BLOCO SIMULINK AC2}

O bloco AC2 incorpora dois equipamentos, o variador de frequência e o motor de indução e ainda inputs e outputs, que servem para controlar e monitorizar o sistema. Relativamente aos inputs de controle, faz-se referência ao Setpoint de velocidade que foi já indicado na figura 12 , que vai servir de base à aceleração/desaceleração do sistema, bem como à sua velocidade permanente e ainda o binário resistente, gerado pelo sistema mecânico (output da caixa redutora).

O bloco AC2 permite ainda escolher o input mecânico, que poderia ser a velocidade de rotação ou binário resistente.
Optou-se por adoptar o binário resistente como input mecânico. Como num elevador a velocidade é imposta, o que vai variar no sistema é o binário resistente que depende da carga total e poderá variar em cada viagem do elevador. O bloco AC2 vai gerar a velocidade de rotação que serve de input ao bloco da caixa redutora, que é velocidade real do sistema. A velocidade real depende de todas as grandezas mecânicas e eléctricas do sistema, bem como do Setpoint de velocidade. Existem ainda vários outputs de controlo ou meramente indicativos e para monitorização do sistema.

$\mathrm{Na}$ janela de parametrização do motor assíncrono, são introduzidos todos os dados que caracterizam a máquina, eléctricos e mecânicos. Foram considerados os parâmetros recolhidos do ascensor real estudado.

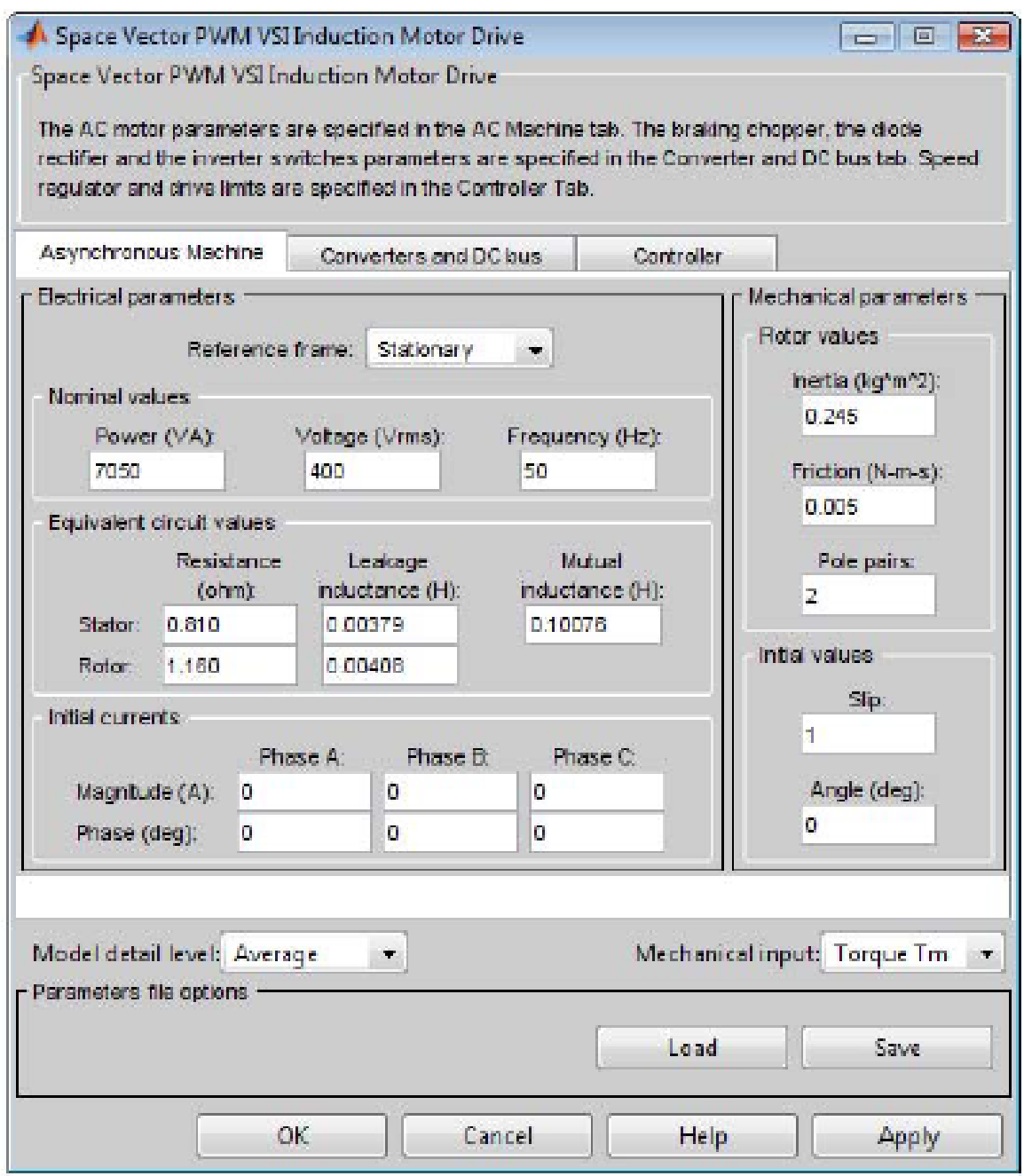

Figura 14 - Janela de parametrização do motor de indução trifásico 
$\mathrm{Na}$ janela de parametrização do conversor e barramento DC, indicada na figura 15 , faz-se especial referência à capacidade do barramento que é a responsável pelo filtro dos harmónicos e consequente estabilização de correntes, e à frequência de comutação do chopper

Quanto mais elevada for esta frequência de comutação, mais precisa será a onda gerada pelo conversor e consequente maior será a estabilidade mecânica do sistema.

No bloco de parametrização do controlador, indicado na figura 16, será definida a forma como irá actuar o variador no motor, ou seja, a rapidez de resposta a alterações de velocidade provocadas pelo binário resistente e Setpoint de velocidade. De referir o controlador $\mathrm{PI}$, a tensão no barramento DC, a aceleração e a desaceleração do motor, os limites de output de frequência e a relação tensão/frequência.

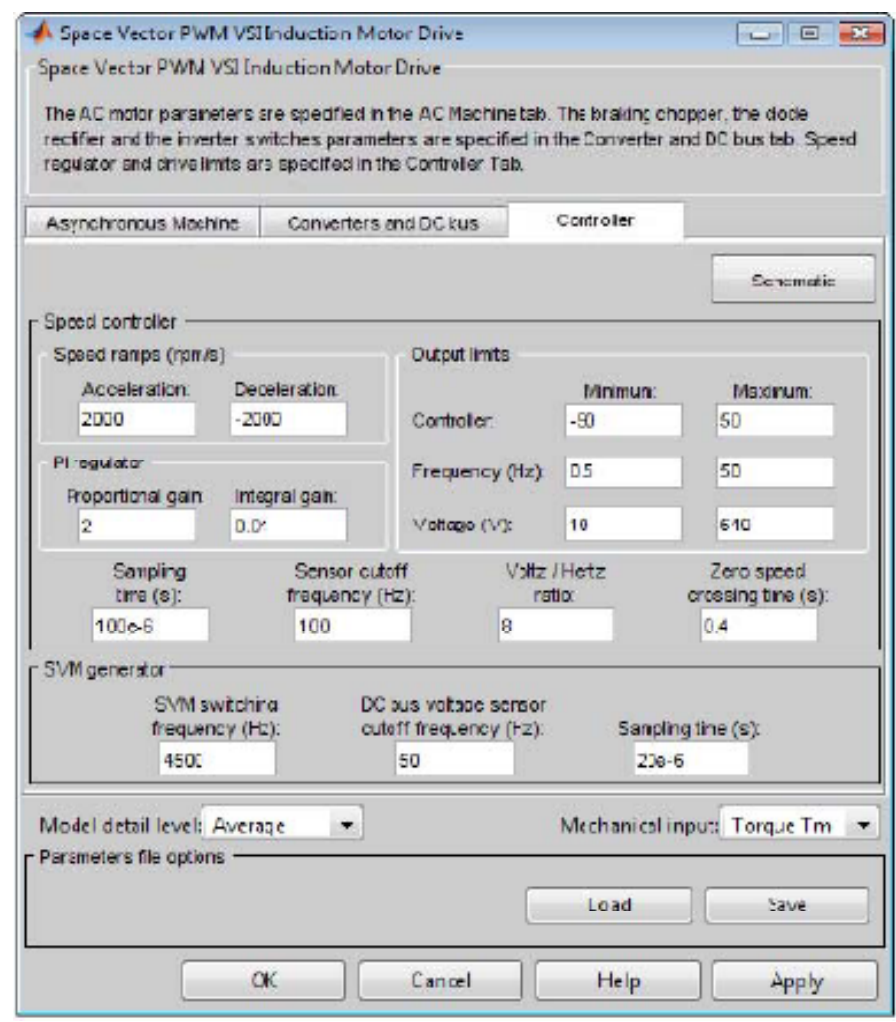

Figura 16 - Janela de parametrização do controlador do sistema variador/motor

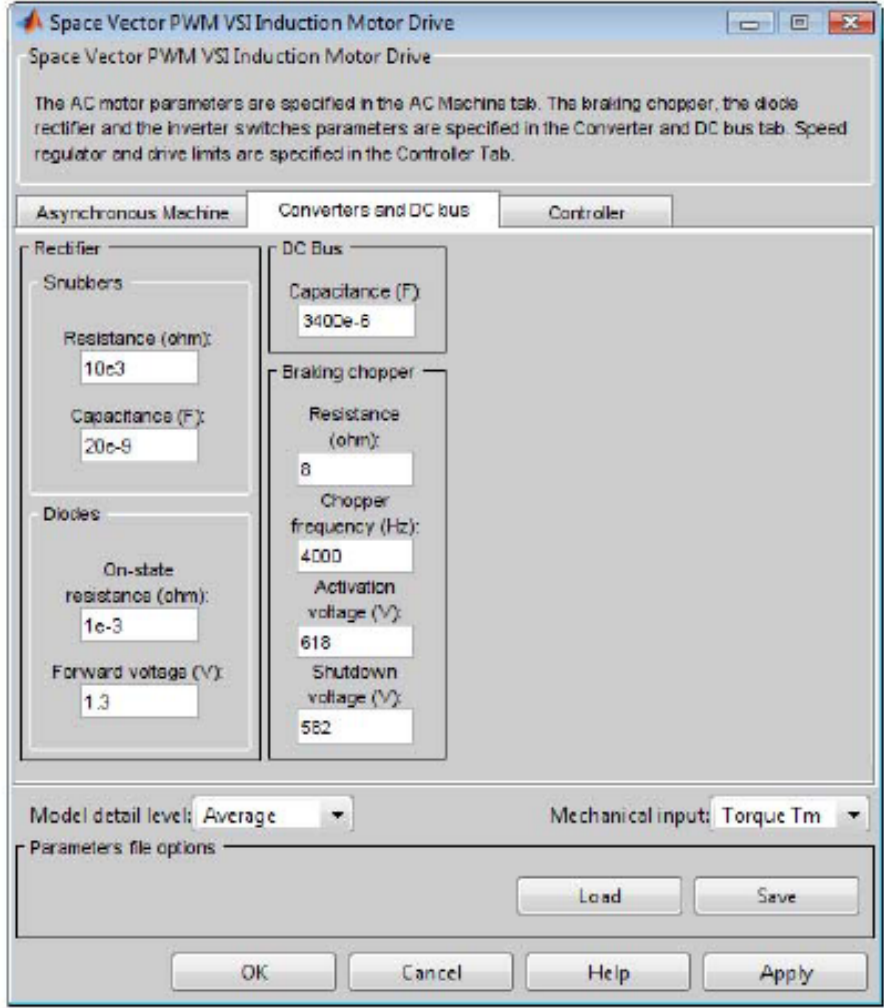

Figura 15 - Janela de parametrização do conversor e barramento DC

\subsubsection{BLOCOS DE MEDIÇÕES DE GRANDEZAS ELÉCTRICAS E} MECÂNICAS

Para efectuar medições aplicaram-se blocos do tipo scope (visualização de outputs) na caixa redutora, com os seguintes agrupamentos de variáveis:

SCOPE 1

- Velocidade linear da cabine $(\mathrm{m} / \mathrm{s})$

SCOPE 2

- Binário resistente / binário electromagnético (N.m)

- Binário transitório (arranque/paragem do sistema) (N.m)

- Potência do sistema mecânico (W)

SCOPE 3

- Corrente no estátor (A)

- Velocidade parametrizada/real (rpm)

- Binário electromagnético (N.m)

SCOPE 4

- Corrente RMS absorvida pelo conjunto variador/motor/sistema mecânico (A) 


\section{VALIDAÇÃo do SimULAdOR}

O ascensor que serviu de base para a modelização em Simulink e para as respectivas medições, é o ascensor número 3 de uma bateria dupla de ascensores produzidos e instalados em 2007 no Alfena Trade Center, em Alfena Ermesinde.

O ascensor seleccionado é um ascensor eléctrico com roda de aderência, com casa de máquinas em cima na vertical, sobre a caixa. A escolha deste tipo de ascensor resulta da lei actualmente em vigor (DL 163/2006 de 08.08), que determina que os ascensores a instalar tenham de ser dimensionados para uma carga de pelo menos $630 \mathrm{~kg} / 8$ pessoas, por forma a garantir o acesso a pessoas com mobilidade reduzida (resulta da imposição das dimensões da cabina que deverá ter no mínimo uma largura de 1,1 m e uma profundidade de 1,4 m).

Os dados medidos e os simulados vão de encontro às mesmas conclusões, com a excepção do modo de frenagem do motor, dado que nas medições não se verifica a reinjecção de energia na rede (uma vez que o variador de frequência utilizado na realidade não o permite).

\section{Hipóteses de Optimização}

\subsection{NO DESENVOLVIMENTO DE NOVOS ASCENSORES:}

1. Aplicação de soluções construtivas mecânicas que permitam reduzir o consumo de energia:

a. Cabinas suspensas ao centro da cabina, pois reduzem o atrito gerado sobre as guias. De acordo com um artigo publicado por Küntscher em 2006, intitulado "Sistemas de Ascensores que poupam energia" em que se comparam diferentes soluções de tracção, será possível fazer a seguinte avaliação energética de ascensores:

i. Para ascensores com máquina com redutor e suspensão lateral, o rendimento da caixa do ascensor será de aproximadamente $70 \%$ e o rendimento da máquina (motor + redutor) também será de aproximadamente $70 \%$, pelo que o rendimento global do sistema será de aproximadamente $50 \%$; ii. Para ascensores com máquina sem redutor e suspensão central, o rendimento da caixa do ascensor será de aproximadamente $85 \%$ e o rendimento da máquina (apenas motor) será de aproximadamente $100 \%$, pelo que o rendimento global do sistema será de aproximadamente 85\%;

Conclusão: O ascensor com suspensão central (e com máquina gearless só consome $60 \%$ da energia (quociente entre $0,5 / 0,85$ ) do ascensor com suspensão lateral;

b. Recurso a roçadeiras ou rodas que gerem menos atrito nas guias;

c. Recurso a cabinas executadas em materiais mais leves, isto é, cabinas menos pesadas, que implicarão contrapesos com menor massa;

d. Recurso a um número reduzido de rodas de desvio. Cada uma destas deverá ter uma baixa inércia;

2. Optimização do peso do contrapeso. De acordo com dados da indústria, o grau de ocupação normal médio da cabina representa apenas $20 \%$ da carga nominal. Contudo, os contrapesos estão dimensionados para uma ocupação média da cabina de $50 \%$ da carga nominal. Uma optimização para cargas mais pequenas, levaria a um melhor balanceamento, e logo a uma poupança da energia necessária;

3. Recurso a máquinas gearless (sem redutor) ou então a máquinas de indução com elevado rendimento;

4. Aplicação do motor linear. Contudo, o estado da arte ainda não corresponde actualmente aos graus de exigência em termos de segurança e perfomance pretendidos;

5. Aplicação de um sistema de reinjecção de energia. Para além da redução do consumo energético directo, este sistema reduz a emissão de calor para a casa de máquinas (elimina-se a energia calorífica libertada na resistência regenerativa) reduzindo os custos com a instalação de um sistema de climatização da casa de máquinas; 
6. Utilização de cabos de suspensão com diâmetros inferiores, bem como formas de gornes nas rodas de tracção que possibilitem a sua aplicação. Esta solução permite a aplicação de diâmetros de rodas de tensão menores, que requerem momentos menores (mas motores com um número de rotações mais elevado);

7. Instalação de ascensores com uma carga nominal inferior, naturalmente tendo em atenção as imposições legais: a NP EN 81-70:2003 indica que um ascensor de $450 \mathrm{~kg}$ é adequado para o transporte de pessoas em cadeiras de rodas. Contudo o Decreto-Lei 163/2006 obriga à instalação de ascensores com um mínimo de $630 \mathrm{~kg}$;

8. Recurso a velocidades nominais inferiores: $v=0,4$ a 0,63 $\mathrm{m} / \mathrm{s}$. Muitas das vezes, principalmente em edifícios de habitação com um número de pisos reduzido, os ascensores têm velocidades de 1,0 m/s, o que implica a instalação de máquinas mais potentes, quando uma velocidade inferior seria mais do que suficiente;

9. Verificação contínua da qualidade da montagem, nomeadamente a colocação das guias - evitar desaprumos e prisões nas guias, bem como a parametrização do variador de frequência e optimização das curvas de andamento;

10. Instalação de sistemas centralizados de gestão de tráfego informatizados que realizem uma avaliação automática do padrão de tráfego. Este sistema de gestão de tráfego disponibilizará então o(s) ascensor(es) necessário(s), optimizando o número de manobras a realizar pelos ascensores e distribuindo os passageiros a transportar pelos diferentes ascensores existentes no edifício.

11. Incorporar o Estado da Arte de Componentes analisados no artigo anterior sobre optimização energética de ascensores

\subsection{DIMENSIONAMENTO E PROJECTO DE EDIFÍCIOS}

Também será possível intervir na fase de projecto de novos edifícios, apresentando informações sobre os consumos energéticos de ascensores aos projectistas.

Actualmente a escolha do tipo (essencialmente o sistema de traç̧ão, a carga nominal e a velocidade) e da quantidade de ascensores para um dado edifício é feita por recurso a modernos programas de cálculo de tráfego, que se baseiam em critérios de qualidade de serviço que se pretende garantir.

De acordo, por exemplo, com a Norma Portuguesa NP4267 "Critérios de escolha de ascensores a instalar em edifícios não destinados a habitação", deverão ser utilizados os seguintes parâmetros (que serão calculados através de modelos matemáticos igualmente definidos na mesma norma) para a aferição dos critérios de qualidade de serviço:

- A duração máxima do percurso teórico (TD), ou seja o tempo de percurso teórico entre pisos extremos.

- O Intervalo máximo no piso principal (I), ou seja, o tempo médio entre as partidas sucessivas da mesma cabina do piso principal;

- A capacidade de transporte (C5), que representa a percentagem da população do edifício acima do piso principal que pode ser transportada em 5 minutos pela bateria de ascensores;

o projectista dimensiona, então os ascensores em função dos valores obtidos pelo cálculo, por comparação com critérios tabelados (por exemplo a TD deverá ser de 20 segundos, no máximo, para que a qualidade do serviço possa ser considerada excelente), sem ter em conta a eficiência energética dos mesmos.

Perante a instalação cada vez maior de ascensores, mesmo em edifícios com baixo número de pisos (para facilitar a mobilidade de pessoas com mobilidade reduzida), dever-seá ter um cuidado especial no seu planeamento (projecto), para se obter uma boa solução, quer do ponto de vista técnico, legal ${ }^{4}$ e económico, quer do ponto de vista energético. 
A partir do simulador apresentado também no artigo anterior, deverá ser possível obter informação sobre os consumos energéticos das diferentes soluções estudadas e incorporá-las nos estudos de tráfego a realizar. Igualmente deverão ser elaboradas tabelas com informação sobre o desempenho energético das diferentes soluções oferecidas, que deverão ser disponibilizadas aos projectistas.

\section{Resultados}

1. Impacto de diferentes massas do contrapeso sobre o consumo energético

Para a verificação do impacto de diferentes massas do contrapeso sobre o consumo energético estudaram-se 3 cenários:

a. cenário ideal - $100 \%$ da energia é reinjectada;

b. cenário real - 30\% da energia é reinjectada;

c. cenário real - não existe reinjecção.

Tomou-se como base o ascensor de $630 \mathrm{~kg}$ a que corresponde uma cabina com $850 \mathrm{~kg}$ de peso e um contrapeso com $1165 \mathrm{~kg}$. Utilizou-se a manobra de referência indicada na norma VDI 4707.

A solução óptima da massa do contrapeso ocorre, para todos os cenários considerados, aos $910 \mathrm{~kg}$ (ou seja quando o contrapeso assume um peso de $78 \%$ de $1165 \mathrm{~kg}$, que é a solução inicialmente estudada).

Os 910 kg correspondem à situação em que não há consumo de energia à subida na manobra com a cabina vazia ${ }^{5}$.

Para cenários com e sem reinjecção de energia, a eficiência torna-se efectiva para massas do contrapeso superiores a $73 \%$ e inferiores a $100 \%$ da massa do contrapeso de referência.

A melhor solução ocorre quando o contrapeso pesa $910 \mathrm{~kg}$. Contudo, esta solução implicará a aplicação de uma máquina mais potente do que a que seria necessária na solução base (1165 kg).

Se fosse possível reaproveitar toda a energia nas manobras que o permitem, o contrapeso poderia assumir qualquer massa acima dos $50 \%$ (ou seja $582,5 \mathrm{~kg}$ ). Para este cenário a solução óptima passaria por um contrapeso com uma massa de $1165 \mathrm{~kg}$, porque implicaria uma máquina de menor potência.

Se fosse possível reaproveitar toda a energia nas manobras que o permitem, o contrapeso poderia assumir qualquer massa acima dos $50 \%$ (ou seja $582,5 \mathrm{~kg}$ ).

Para este cenário a solução óptima passaria por um contrapeso com uma massa de $1165 \mathrm{~kg}$, porque implicaria uma máquina de menor potência.

Tabela 2 - Resultados: Impacto de diferentes massas do contrapeso sobre o consumo energético

\begin{tabular}{|c|c|c|c|c|c|c|c|c|c|c|c|c|c|c|c|c|c|c|c|}
\hline \multicolumn{2}{|c|}{ Carga } & \multicolumn{18}{|c|}{ Energia da Manobra de Referência em Função da Massa do Contrapeso } \\
\hline \multirow{3}{*}{ Massa } & \multirow{3}{*}{$\%$} & \multirow{2}{*}{\multicolumn{2}{|c|}{$\begin{array}{c}\text { Contrapeso } 0 \% \\
0 \mathrm{~kg}\end{array}$}} & \multirow{2}{*}{\multicolumn{2}{|c|}{$\begin{array}{c}\text { Contrapeso } 25 \% \\
291,25 \mathrm{~kg}\end{array}$}} & \multicolumn{2}{|c|}{ Contrapeso $50 \%$} & \multicolumn{2}{|c|}{ Contrapeso 68\% (a) } & \multirow{2}{*}{\multicolumn{2}{|c|}{$\begin{array}{c}\text { Contrapeso=Cabine } \\
73 \% \\
850 \mathrm{~kg}\end{array}$}} & \multicolumn{2}{|c|}{ Contrapeso $75 \%$} & \multicolumn{2}{|c|}{ Contrapeso $78 \%$ (b) } & \multicolumn{2}{|c|}{ Contrapeso $95 \%$} & \multicolumn{2}{|c|}{ Contrapeso $100 \%$ (c) } \\
\hline & & & & & & \multicolumn{2}{|c|}{$582,5 \mathrm{~kg}$} & \multicolumn{2}{|c|}{$790 \mathrm{~kg}$} & & & \multicolumn{2}{|c|}{$873,75 \mathrm{~kg}$} & \multicolumn{2}{|c|}{$910 \mathrm{~kg}$} & \multicolumn{2}{|c|}{$1102 \mathrm{~kg}$} & \multicolumn{2}{|c|}{$1165 \mathrm{~kg}$} \\
\hline & & Subida & \begin{tabular}{|l|} 
Descida \\
\end{tabular} & Subida & Descida & Subida & Descida & Subida & \begin{tabular}{|l|} 
Descida \\
\end{tabular} & Subida & Descida & Subida & Descida & Subida & \begin{tabular}{|l|} 
Descida \\
\end{tabular} & Subida & \begin{tabular}{|l|} 
Descida \\
\end{tabular} & Subida & Descida \\
\hline $0,0 \mathrm{~kg}$ & $0 \%$ & $34,16 \mathrm{Wh}$ & & $23,10 \mathrm{Wh}$ & $\frac{-18,10 \mathrm{Wh}}{-0371 \mathrm{Wh}}$ & $\begin{array}{ll}12,17 \mathrm{Wh} \\
1,0 \mathrm{Wh}\end{array}$ & $\frac{-7,58 \mathrm{Wh}}{.1220 \mathrm{wh}}$ & $\begin{array}{ll}4,55 \mathrm{Wh} \\
, 03 \mathrm{Wh}\end{array}$ & $\begin{array}{l}0,00 \mathrm{Wh} \\
576 \mathrm{Wh}\end{array}$ & $2,23 \mathrm{Wh}$ & $2,23 \mathrm{Wh}$ & $\frac{1,35 \mathrm{Wh}}{710 \mathrm{Wh}}$ & $3,11 \mathrm{Wh}$ & \begin{tabular}{|l}
$0,00 \mathrm{Wh}$ \\
$58 \mathrm{Wh}$
\end{tabular} & $4,45 \mathrm{Wh}$ & $-7,02 \mathrm{Wh}$ & \begin{tabular}{|l|l|}
$11,59 \mathrm{Wh}$ \\
$5,33 \mathrm{Wh}$
\end{tabular} & $\frac{-9,31 \mathrm{Wh}}{-357 \mathrm{Wh}}$ & \\
\hline $157,5 \mathrm{~kg}$ & $25 \%$ & $40,20 \mathrm{Wh}$ & & $29,06 \mathrm{Wh}$ & $-23,71 \mathrm{Wh}$ & $18,06 \mathrm{Wh}$ & $-13,29 \mathrm{Wh}$ & $10,30 \mathrm{Wh}$ & $-5,76 \mathrm{Wh}$ & $8,07 \mathrm{Wh}$ & $-0,57 \mathrm{Wh}$ & $7,19 \mathrm{Wh}$ & & \begin{tabular}{|l|l|}
$5,84 \mathrm{Wh}$ \\
1,70
\end{tabular} & & \begin{tabular}{|l|l|}
$-1,26 \mathrm{Wh}$ \\
\end{tabular} & 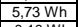 & $57 \mathrm{Wh}$ & $8,07 \mathrm{Wh}$ \\
\hline $315,0 \mathrm{~kg}$ & $50 \%$ & $\begin{array}{ll}46,28 \mathrm{Wh} \\
5200\end{array}$ & \begin{tabular}{|l}
$-34,64 \mathrm{Wh}$ \\
\end{tabular} & $35,06 \mathrm{Wh}$ & $\begin{array}{l}-29,24 \mathrm{Wh} \\
-3458 \mathrm{Wh}\end{array}$ & \begin{tabular}{|l|}
$24,00 \mathrm{Wh}$ \\
$2996 \mathrm{Wh}$
\end{tabular} & $\begin{array}{l}-18,95 \mathrm{Wh} \\
-.245 \mathrm{Wh}\end{array}$ & \begin{tabular}{|l|}
$16,19 \mathrm{Wh}$ \\
$2210 \mathrm{Wh}$
\end{tabular} & $\begin{array}{l}-11,49 \mathrm{Wh} \\
-.1716 \mathrm{Wh}\end{array}$ & $\begin{array}{ll}13,94 \mathrm{Wh} \\
195 \mathrm{Whb}\end{array}$ & $\begin{array}{l}-9,31 \mathrm{Wh} \\
-1500 \mathrm{Wh} \\
\end{array}$ & $13,05 \mathrm{Wh}$ & $\frac{-8,45 \mathrm{Wh}}{-.14 .15 \mathrm{Wh}}$ & \begin{tabular}{|l}
$11,70 \mathrm{Wh}$ \\
$1759 \mathrm{Wh}$
\end{tabular} & \begin{tabular}{|l}
$-7,13 \mathrm{Wh}$ \\
$-12,84 \mathrm{Wh}$
\end{tabular} & \begin{tabular}{|l|l}
$4,56 \mathrm{Wh}$ \\
$10,41 \mathrm{Wh}$
\end{tabular} & \begin{tabular}{|l|l|}
$-0,10 \mathrm{Wh}$ \\
$-5,87 \mathrm{Wh}$ \\
\end{tabular} & $\frac{2,23 \mathrm{Wh}}{8,07 \mathrm{Wh}}$ & $\begin{array}{ll}2,23 \mathrm{Wh} \\
-3,57 \mathrm{Wh}\end{array}$ \\
\hline$\frac{472,5 \mathrm{~kg}}{630,0 \mathrm{~kg}}$ & $\begin{array}{ll}75 \% \\
100 \% \\
\end{array}$ & $\begin{array}{ll}52,40 \mathrm{Wh} \\
58,57 \mathrm{Wh}\end{array}$ & \begin{tabular}{|l|l|l|l|l}
$-39,29 \mathrm{Wh}$ \\
$-50,72 \mathrm{Wh}$ \\
\end{tabular} & \begin{tabular}{|l|l|l|l|l|l|}
$41,11 \mathrm{Wh}$ \\
$47,20 \mathrm{Wh}$
\end{tabular} & $\begin{array}{l}-34,58 \mathrm{Wh} \\
-34,28 \mathrm{Wh}\end{array}$ & $\begin{array}{ll}29,96 \mathrm{Wh} \\
35,97 \mathrm{Wh} \\
\end{array}$ & $\begin{array}{l}-24,55 \mathrm{Wh} \\
-30,07 \mathrm{Wh}\end{array}$ & \begin{tabular}{l|l}
$22,10 \mathrm{Wh}$ \\
$28,07 \mathrm{Wh}$
\end{tabular} & $\begin{array}{l}-\frac{-17,16 \mathrm{Wh}}{-22,78 \mathrm{Wh}} \\
\end{array}$ & $\begin{array}{ll}19,85 \mathrm{Wh} \\
25,79 \mathrm{Wh}\end{array}$ & \begin{tabular}{|l}
$-15,00 \mathrm{Wh}$ \\
$-20,65 \mathrm{Wh}$
\end{tabular} & $\begin{array}{ll}18,96 \mathrm{Wh} \\
24,89 \mathrm{Wh}\end{array}$ & $\begin{array}{l}-14,15 \mathrm{Wh} \\
-19,80 \mathrm{Wh}\end{array}$ & $\frac{17,59 \mathrm{Wh}}{23,52 \mathrm{Wh}}$ & \begin{tabular}{|l}
$-12,84 \mathrm{Wh}$ \\
$-18,50 \mathrm{Wh}$
\end{tabular} & \begin{tabular}{|l|l|}
$10,41 \mathrm{Wh}$ \\
$16,30 \mathrm{Wh}$
\end{tabular} & \begin{tabular}{|l|l|}
$-5,87 \mathrm{Wh}$ \\
$-11,59 \mathrm{Wh}$ \\
\end{tabular} & $\frac{8,07 \mathrm{Wh}}{13,94 \mathrm{Wh}}$ & $\begin{array}{l}-3,57 \mathrm{Wh} \\
-9,31 \mathrm{Wh}\end{array}$ \\
\hline $\begin{array}{l}\text { Média po } \\
\text { VDI } 4\end{array}$ & nderada & $39,008 \mathrm{Wh}$ & $-31,741 \mathrm{wh}$ & $27,885 \mathrm{Wh}$ & $-22,545 \mathrm{Wh}$ & $16,899 \mathrm{Wh}$ & $-12,129 \mathrm{Wh}$ & 9,195 Wh & $-4,593 \mathrm{Wh}$ & 6,914 Wh & $-1,487 \mathrm{Wh}$ & 6,031 Wh & $-1,514 \mathrm{Wh}$ & $4,681 \mathrm{Wh}$ & $-0,181 \mathrm{Wh}$ & $-2,389 \mathrm{wh}$ & 6,917 Wh & $-4,695 \mathrm{Wh}$ & 9,257 Wh \\
\hline \multirow{2}{*}{\multicolumn{2}{|c|}{$\begin{array}{l}\text { Ideal-100\% } \\
\text { Reinjecção }\end{array}$}} & \multicolumn{2}{|c|}{$7,267 \mathrm{Wh}$} & \multicolumn{2}{|c|}{$5,340 \mathrm{Wh}$} & \multicolumn{2}{|c|}{$4,770 \mathrm{Wh}$} & \multicolumn{2}{|c|}{ 4,601 Wh } & \multicolumn{2}{|c|}{$5,428 \mathrm{Wh}$} & \multicolumn{2}{|c|}{ 4,517 Wh } & \multicolumn{2}{|c|}{$4,500 \mathrm{Wh}$} & \multicolumn{2}{|c|}{$4,528 \mathrm{Wh}$} & \multirow{2}{*}{\multicolumn{2}{|c|}{$\begin{array}{c}4,562 \text { Wh } \\
100,00 \%\end{array}$}} \\
\hline & & 159 & $31 \%$ & 117. & $06 \%$ & 104, & & 100,8 & & 118, & & 99,6 & & 98, & $65 \%$ & 99,2 & & & \\
\hline \multirow{2}{*}{\multicolumn{2}{|c|}{ 30\% Reinjecção }} & \multicolumn{2}{|c|}{$29,486 \mathrm{Wh}$} & 21,12 & $2 \mathrm{Wh}$ & 13,26 & $0 \mathrm{Wh}$ & 7,817 & $7 \mathrm{Wh}$ & 6,468 & $8 \mathrm{Wh}$ & 5,57 & $7 \mathrm{Wh}$ & 4,62 & $7 \mathrm{Wh}$ & 6,201 & $1 \mathrm{Wh}$ & 7,84 & $8 w h$ \\
\hline & & 375, & $69 \%$ & 269 & $12 \%$ & 168 & & 99,5 & $59 \%$ & 82,4 & & 71,6 & $6 \%$ & 58 & $95 \%$ & 79,0 & & & $00 \%$ \\
\hline em Rein & jecção & 39,00 & $18 \mathrm{Wh}$ & $27,8 \varepsilon$ & $5 \mathrm{Wh}$ & 16,89 & $9 \mathrm{Wh}$ & 9,195 & $5 \mathrm{Wh}$ & 6,914 & $4 \mathrm{Wh}$ & 6,03 & I Wh & 4,68 & $1 \mathrm{Wh}$ & 6,917 & $7 \mathrm{Wh}$ & 9,25 & $7 W h$ \\
\hline & & 421, & $39 \%$ & 301 & $23 \%$ & 182 & $56 \%$ & 99,3 & $33 \%$ & 74,6 & & 65 & $5 \%$ & 50 & $57 \%$ & 74,7 & $72 \%$ & & $00 \%$ \\
\hline
\end{tabular}

\footnotetext{
${ }^{4}$ Existem normas que definem determinados requisitos mínimos que têm de ser cumpridos pelos ascensores, por exemplo em termos de capacidade de carga. Assim, desde Fevereiro de 2007, todos os novos ascensores devem obedecer à nova legislação (DL163/2006), que regula as acessibilidades a pessoas com mobilidade reduzida. Esta norma obriga à instalação de ascensores com uma cabina mínima de $1.100 \mathrm{~mm} \times 1.400 \mathrm{~mm}$ (largura $\mathrm{x}$ profundidade), a que corresponde uma carga nominal mínima de 8 pessoas-630 kg. Para unidades de saúde, como hospitais existem outras normas portuguesas que sugerem a instalação de ascensores monta-camas para uma carga nominal de 21 pessoas $-1.600 \mathrm{~kg}$.

${ }^{5}$ Como se verá adiante, esta solução não poderá ser adoptada, por não cumprir os requisitos de aderência impostos pela norma NP EN 811:2000.
} 


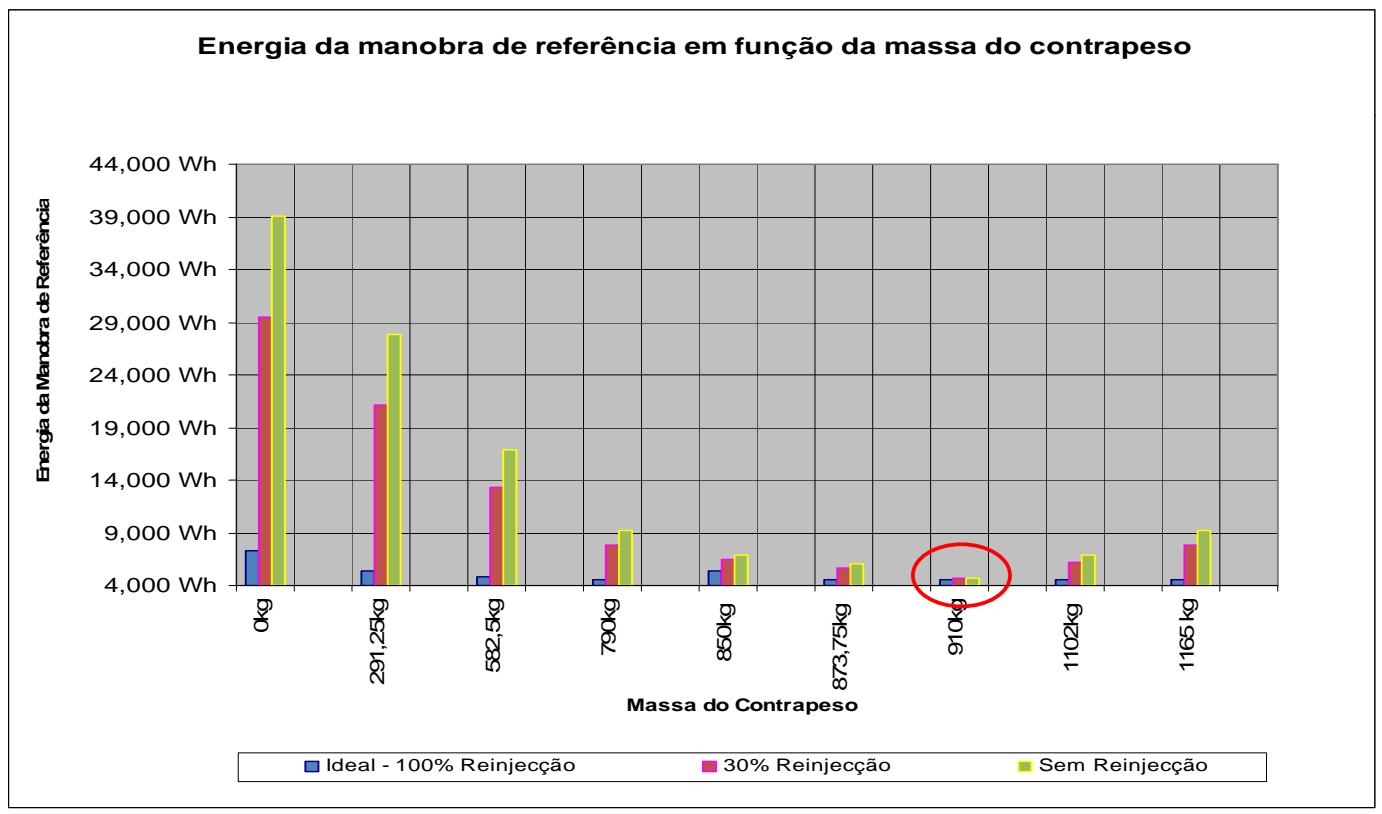

Figura 17 - Impacto de diferentes massas do contrapeso sobre o consumo energético

2. Impacto da optimização do peso das cabinas sobre o consumo energético:

Tomou-se por base um ascensor idêntico ao utilizado para validar o modelo em Matlab-Simulink, com as características ao lado indicadas.

Verificou-se que não é suficiente analisar apenas o impacto que implicará a redução da massa da cabina, de per se.

Ter-se-á de ter em conta também as recomendações em termos de aderência na roda de tracção da máquina, indicadas pela norma NP EN 81-1:2000 - Anexo $\mathrm{M}^{6}$.

Local da casa das máquinas: Em cima na vertical, sobre a caixa Carga nominal: $630 \mathrm{Kg} / 8$ Pessoas

Curso: $20,79 \mathrm{~m}$

Velocidade nominal: $1,0 \mathrm{~m} / \mathrm{s}$ VVF

Tipo de Suspensẫo: $1: 1$

Diâmetro dos cabos $8 \mathrm{~mm}$

Diâmetro da roda de tracçã $: 400 \mathrm{~mm}$

Abraçamento: $165^{\circ}$

Tipo de gorne: em U

Ângulo do gome: $25^{\circ}$

Ângulo do gome subtalhado: $90,88^{\circ}$

Relação diametro cabo vs diametro roda de tracção: 50

Diâmetro da roda de desvio: $320 \mathrm{~mm}$

Com base nestas duas premissas foram obtidos os resultados indicados na tabela 3.

Tabela 3: Resultados: Impacto da optimização do peso das cabinas sobre o consumo energético

\begin{tabular}{|c|c|c|c|c|}
\hline $\begin{array}{c}\text { Contrapeso } \\
\text { da carga nominal } \\
\text { da cabina }\end{array}$ & $\begin{array}{c}\text { Peso Mínimo } \\
\text { Cabina } \\
(\mathbf{k g})\end{array}$ & $\begin{array}{c}\text { Peso do } \\
\text { Contrapeso } \\
\mathbf{( k g )}\end{array}$ & $\begin{array}{c}\text { Quantidade } \\
\text { Cabos }\end{array}$ & $\begin{array}{c}\text { Diferença face } \\
\text { à solução base } \\
\text { (kg) }\end{array}$ \\
\hline 100 & 1750 & 2380 & 7 & 2015 \\
\hline 90 & 1550 & 2117 & 6 & 1552 \\
\hline 80 & 1400 & 1904 & 6 & 1189 \\
\hline 70 & 1250 & 1691 & 6 & 826 \\
\hline 60 & 1050 & 1428 & 5 & 363 \\
\hline $\mathbf{5 0}$ & $\mathbf{9 0 0}$ & $\mathbf{1 2 1 5}$ & $\mathbf{5}$ & $\mathbf{0}$ \\
\hline 40 & 800 & 1052 & 4 & -263 \\
\hline 30 & 1050 & 1239 & 5 & 174 \\
\hline 20 & 1300 & 1426 & 6 & 611 \\
\hline 10 & 1500 & 1563 & 6 & 948 \\
\hline 0 & 1750 & 1750 & 7 & 1385 \\
\hline
\end{tabular}

6 O Anexo M desta norma, descreve a metodologia a seguir para calcular a aderência dos cabos na roda de tracção, tendo em conta o curso, o carregamento da cabina, a desaceleração motivada por uma paragem de emergência, o tipo de gorne, o ângulo do gorne, o coeficiente de atrito, o diâmetro da roda de tracção, o diâmetro da roda de desvio, o ângulo do gorne subtalhado, etc. 


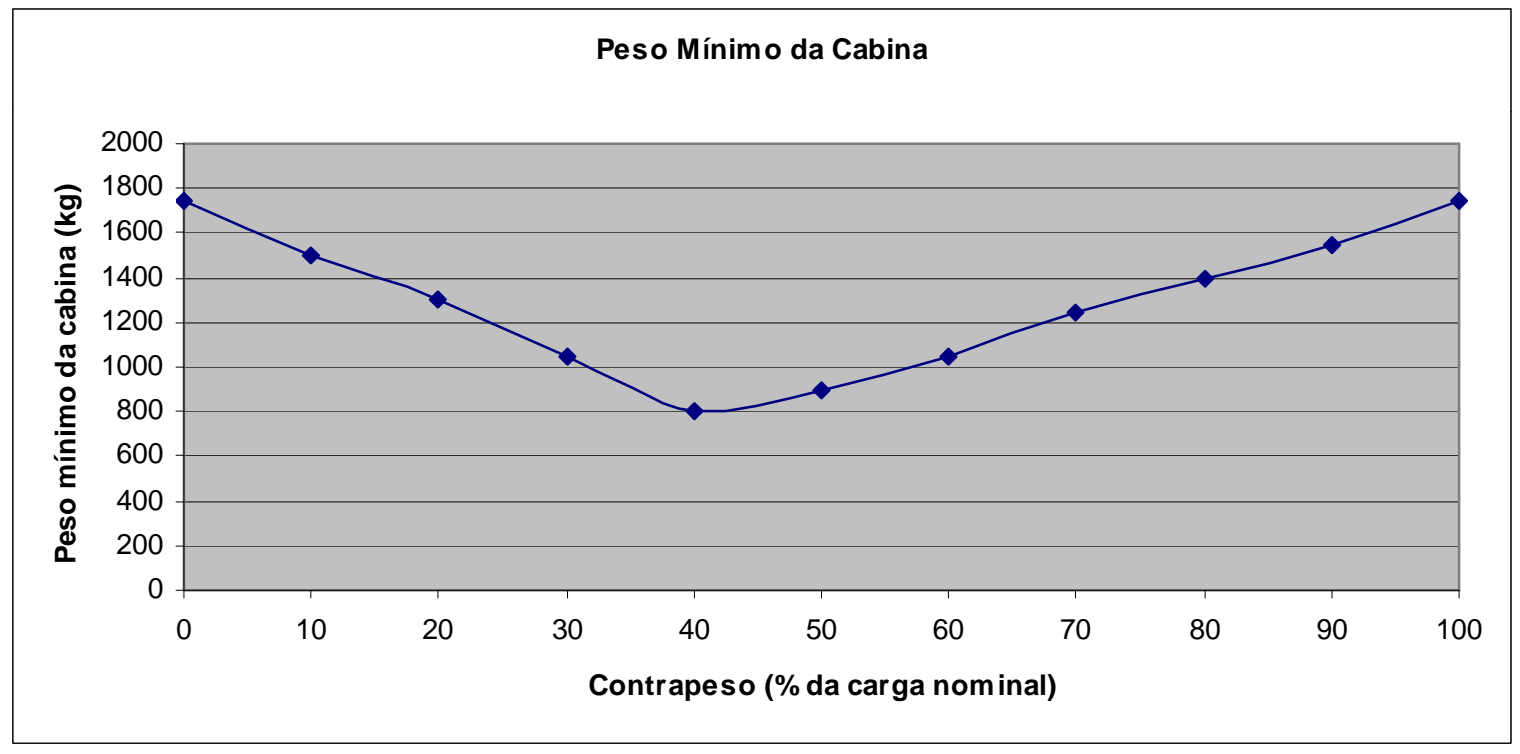

Figura 18 - Peso mínimo da cabina

Pode-se concluir, que o ponto que permitirá optimizar o peso da cabina e o consumo energético do ascensor ocorre, quando a cabina pesar $800 \mathrm{~kg}$ e o contrapeso $1052 \mathrm{~kg}$.

Ou seja dever-se-á adoptar uma solução em que o contrapeso compense o peso da cabina $+40 \%$ da carga nominal da mesma, e não a solução utilizada presentemente nos ascensores produzidos maioritariamente pela indústria, que prevê um contrapeso que compensa o peso da cabina + $50 \%$ da carga nominal da mesma (pesando a cabina $900 \mathrm{~kg}$ e o contrapeso $1215 \mathrm{~kg}$ ).

Para um ascensor com um contrapeso que compense o peso da cabina $+40 \%$ da carga nominal da cabina, o consumo energético será de 6,917 Wh para uma manobra de referência, em vez de 9,257 Wh, na solução adoptada actualmente. Ou seja, conseguir-se-á uma redução de aproximadamente $26 \%$ no consumo de energia.

Com esta solução seria igualmente possível poupar 263 kg de aço, em todo o sistema (cabina e contrapeso). Acresce ainda o facto de acordo com a norma EN81:2000 - Anexo M, ser possível para esta solução aplicar 4 cabos de $8 \mathrm{~mm}^{2}$ em vez dos 5 cabos de $8 \mathrm{~mm}^{2}$ que são normalmente aplicados.
Ou seja com a optimização do peso da cabina, conseguir-se-á não só uma redução do consumo energético, mas também uma redução no custo dos materiais a aplicar.

\section{Suspensão lateral vs suspensão central}

Pretendeu-se avaliar o impacto que o tipo de suspensão da cabina tem sobre o consumo energético.

Viu-se no ponto 4.1, que num estudo publicado por Küntscher (2006), o rendimento da caixa do ascensor será de aproximadamente $70 \%$, quando a cabina é suspensa lateralmente e de aproximadamente $85 \%$, quando a cabina é suspensa centralmente.

Recorrendo ao simulador desenvolvido verificou-se que a solução da suspensão central, por permitir uma redução do atrito nas guias, implicou uma poupança de $16 \%$ em termos energéticos em relação à solução da suspensão lateral da cabina, para o ascensor de $630 \mathrm{~kg}$ estudado, pelo que se recomenda a sua adopção. 
Tabela 4 - Resultados: suspensão lateral vs suspensão central

\begin{tabular}{|c|c|c|c|c|c|}
\hline \multirow{2}{*}{ Carga } & \multicolumn{3}{c|}{ Energia da Manobra de Referência em Função da } \\
Suspensão da Cabine
\end{tabular}

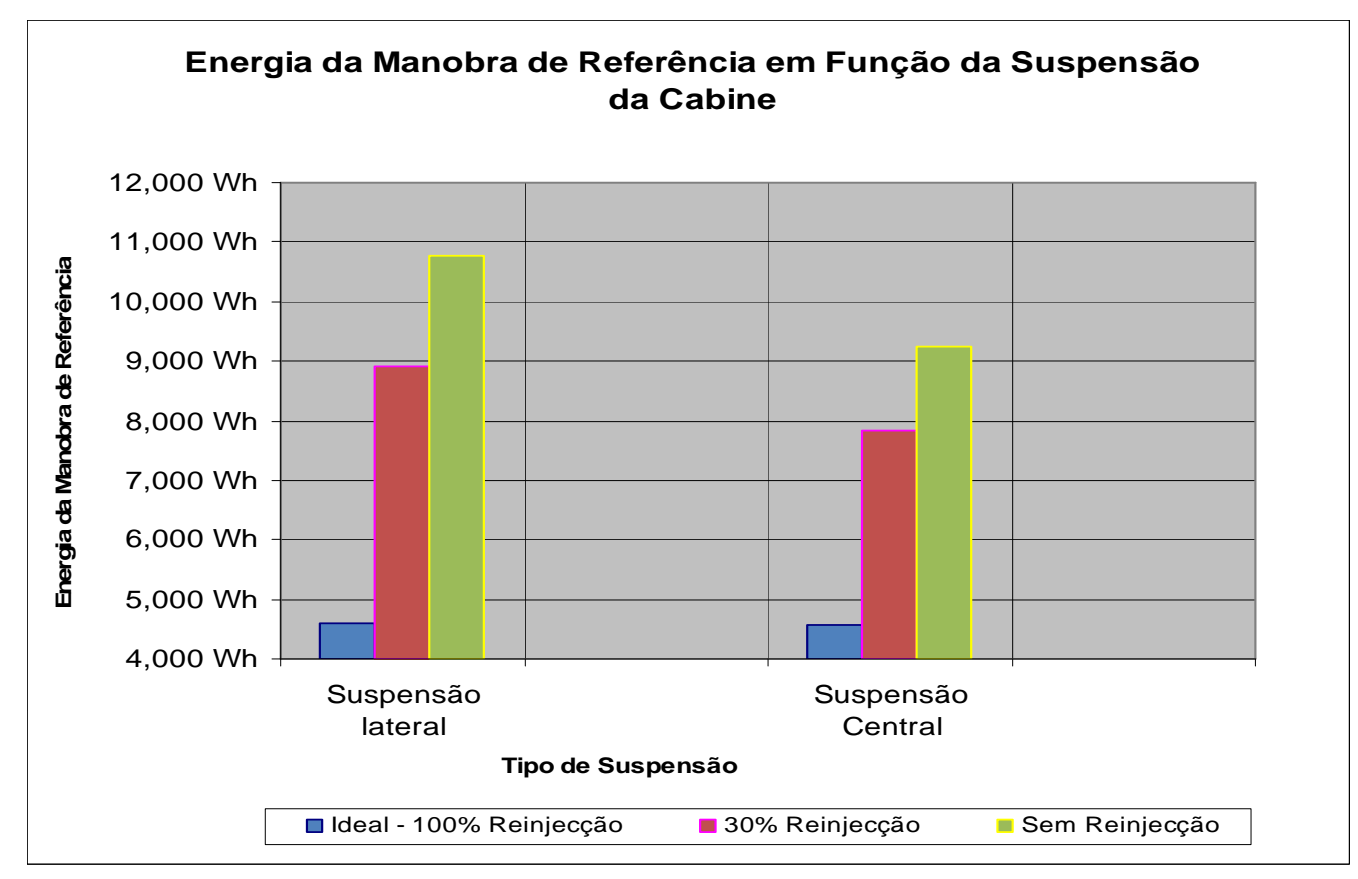

Figura 19 - Suspensão lateral vs suspensão central 
4. Impacto da redução da velocidade linear do ascensor no consumo energético:

Mantendo todas as características técnicas do ascensor, com excepção da velocidade (o que implicou uma mudança na relação da caixa redutora, mantendo o mesmo diâmetro da roda de tracção), verifica-se que quanto menor for a velocidade nominal do ascensor (ou seja, a velocidade linear da cabina), menor é o consumo energético. Assim, e por comparação a uma velocidade nominal de $v=1,0 \mathrm{~m} / \mathrm{s}$, conseguir-se-á uma redução de $46 \%$ no consumo energético se a velocidade for reduzida para $\mathrm{v}=0,4 \mathrm{~m} / \mathrm{s}$, ceteris paribus.

Na tabela 4 é possível verificar a poupança que se conseguirá obter mediante a redução da velocidade.

Se fosse possível a reinjecção de toda a energia gerada durante a manobra de referência, não se verificariam variações no consumo energético, com a variação da velocidade linear da cabina.

Tabela 5 - Resultados: Impacto da redução da velocidade linear no consumo energético

\begin{tabular}{|c|c|c|c|c|c|c|c|c|c|c|c|}
\hline \multicolumn{2}{|c|}{ Carga } & \multicolumn{10}{|c|}{ Energia da Manobra de Referência em Função da Velocidade Linear da Cabine } \\
\hline \multirow{3}{*}{ Massa } & \multirow{3}{*}{$\%$} & \multicolumn{10}{|c|}{ Velocidade Linear da Cabine } \\
\hline & & \multicolumn{2}{|c|}{$0,4 \mathrm{~m} / \mathrm{s}$} & \multicolumn{2}{|c|}{$0,5 \mathrm{~m} / \mathrm{s}$} & \multicolumn{2}{|c|}{$0,63 \mathrm{~m} / \mathrm{s}$} & \multicolumn{2}{|c|}{$0,8 \mathrm{~m} / \mathrm{s}$} & \multicolumn{2}{|c|}{$1 \mathrm{~m} / \mathrm{s}$} \\
\hline & & Subida & Descida & Subida & Descida & Subida & Descida & Subida & Descida & Subida & Descida \\
\hline $0,0 \mathrm{~kg}$ & $0 \%$ & $-2,30 \mathrm{Wh}$ & $6,78 \mathrm{Wh}$ & $-3,41 \mathrm{Wh}$ & $7,90 \mathrm{Wh}$ & $-4,87 \mathrm{Wh}$ & $9,39 \mathrm{Wh}$ & $-6,82 \mathrm{Wh}$ & $11,38 \mathrm{Wh}$ & $-9,31 \mathrm{Wh}$ & $13,94 \mathrm{Wh}$ \\
\hline $157,5 \mathrm{~kg}$ & $25 \%$ & $-0,04 \mathrm{Wh}$ & $4,50 \mathrm{Wh}$ & $-0,60 \mathrm{Wh}$ & $5,06 \mathrm{Wh}$ & $-1,33 \mathrm{Wh}$ & $5,80 \mathrm{Wh}$ & $-2,31 \mathrm{Wh}$ & $6,79 \mathrm{Wh}$ & $-3,57 \mathrm{Wh}$ & $8,07 \mathrm{Wh}$ \\
\hline $315,0 \mathrm{~kg}$ & $50 \%$ & $2,23 \mathrm{Wh}$ & $2,23 \mathrm{Wh}$ & $2,23 \mathrm{Wh}$ & $2,23 \mathrm{Wh}$ & $2,23 \mathrm{Wh}$ & $2,23 \mathrm{Wh}$ & $2,23 \mathrm{Wh}$ & $2,23 \mathrm{Wh}$ & $2,23 \mathrm{Wh}$ & $2,23 \mathrm{Wh}$ \\
\hline $472,5 \mathrm{~kg}$ & $75 \%$ & $4,50 \mathrm{Wh}$ & $-0,04 \mathrm{Wh}$ & $5,06 \mathrm{Wh}$ & $-0,60 \mathrm{Wh}$ & $5,80 \mathrm{Wh}$ & $-1,33 \mathrm{Wh}$ & $6,79 \mathrm{Wh}$ & $-2,31 \mathrm{Wh}$ & $8,07 \mathrm{Wh}$ & $-3,57 \mathrm{Wh}$ \\
\hline $630,0 \mathrm{~kg}$ & $100 \%$ & $6,78 \mathrm{Wh}$ & $-2,30 \mathrm{Wh}$ & $7,90 \mathrm{Wh}$ & $-3,41 \mathrm{Wh}$ & $9,39 \mathrm{Wh}$ & $-4,87 \mathrm{Wh}$ & $11,38 \mathrm{Wh}$ & $-6,82 \mathrm{Wh}$ & $13,94 \mathrm{Wh}$ & $-9,31 \mathrm{Wh}$ \\
\hline \multicolumn{2}{|c|}{$\begin{array}{c}\text { Média ponderada } \\
\text { com base na } \\
\text { VDI } 4707\end{array}$} & $-0,487 \mathrm{Wh}$ & $4,958 \mathrm{Wh}$ & $-1,154 \mathrm{Wh}$ & $5,634 \mathrm{Wh}$ & $-2,030 \mathrm{Wh}$ & $6,523 \mathrm{Wh}$ & $-3,200 \mathrm{Wh}$ & $7,720 \mathrm{Wh}$ & $-4,695 \mathrm{Wh}$ & $9,257 \mathrm{Wh}$ \\
\hline \multicolumn{2}{|c|}{$\begin{array}{l}\text { Ideal - 100\% } \\
\text { Reinjecção }\end{array}$} & \multicolumn{2}{|c|}{$\begin{array}{c}\mathbf{4 , 4 7 1} \mathbf{W h} \\
98,01 \%\end{array}$} & \multicolumn{2}{|c|}{$\begin{array}{c}\mathbf{4 , 4 8 0} \mathbf{W h} \\
98,20 \%\end{array}$} & \multicolumn{2}{|c|}{$\begin{array}{c}\mathbf{4 , 4 9 3} \mathbf{W h} \\
98,50 \%\end{array}$} & \multicolumn{2}{|c|}{$\begin{array}{c}\mathbf{4 , 5 2 0 ~ W h} \\
99,08 \%\end{array}$} & \multicolumn{2}{|c|}{$\begin{array}{c}\mathbf{4 , 5 6 2} \mathbf{W h} \\
100,00 \%\end{array}$} \\
\hline \multicolumn{2}{|c|}{ 30\% Reinjecção } & \multicolumn{2}{|c|}{$\begin{array}{c}\mathbf{4 , 8 1 2} \mathbf{W h} \\
61,31 \%\end{array}$} & \multicolumn{2}{|c|}{$\begin{array}{c}\mathbf{5 , 2 8 7} \mathbf{W h} \\
67,37 \%\end{array}$} & \multicolumn{2}{|c|}{$\begin{array}{c}\mathbf{5 , 9 1 4} \mathbf{W h} \\
75,36 \%\end{array}$} & \multicolumn{2}{|c|}{$\begin{array}{c}\mathbf{6 , 7 6 0} \mathbf{W h} \\
86,13 \%\end{array}$} & \multicolumn{2}{|c|}{$\begin{array}{c}7,848 \boldsymbol{W h} \\
100,00 \%\end{array}$} \\
\hline \multicolumn{2}{|c|}{ Sem Reinjecção } & \multicolumn{2}{|c|}{$\begin{array}{c}\text { 4,958 Wh } \\
53,56 \%\end{array}$} & \multicolumn{2}{|c|}{$\begin{array}{c}\mathbf{5 , 6 3 4} \mathbf{W h} \\
60,86 \%\end{array}$} & \multicolumn{2}{|c|}{$\begin{array}{c}\mathbf{6 , 5 2 3} \mathbf{W h} \\
70,47 \%\end{array}$} & \multicolumn{2}{|c|}{$\begin{array}{c}7,720 \text { Wh } \\
83,39 \%\end{array}$} & \multicolumn{2}{|c|}{$\begin{array}{c}9,257 \text { Wh } \\
100,00 \%\end{array}$} \\
\hline
\end{tabular}

\section{Energia da Manobra de Referência em Função da Velocidade Linear da Cabine}

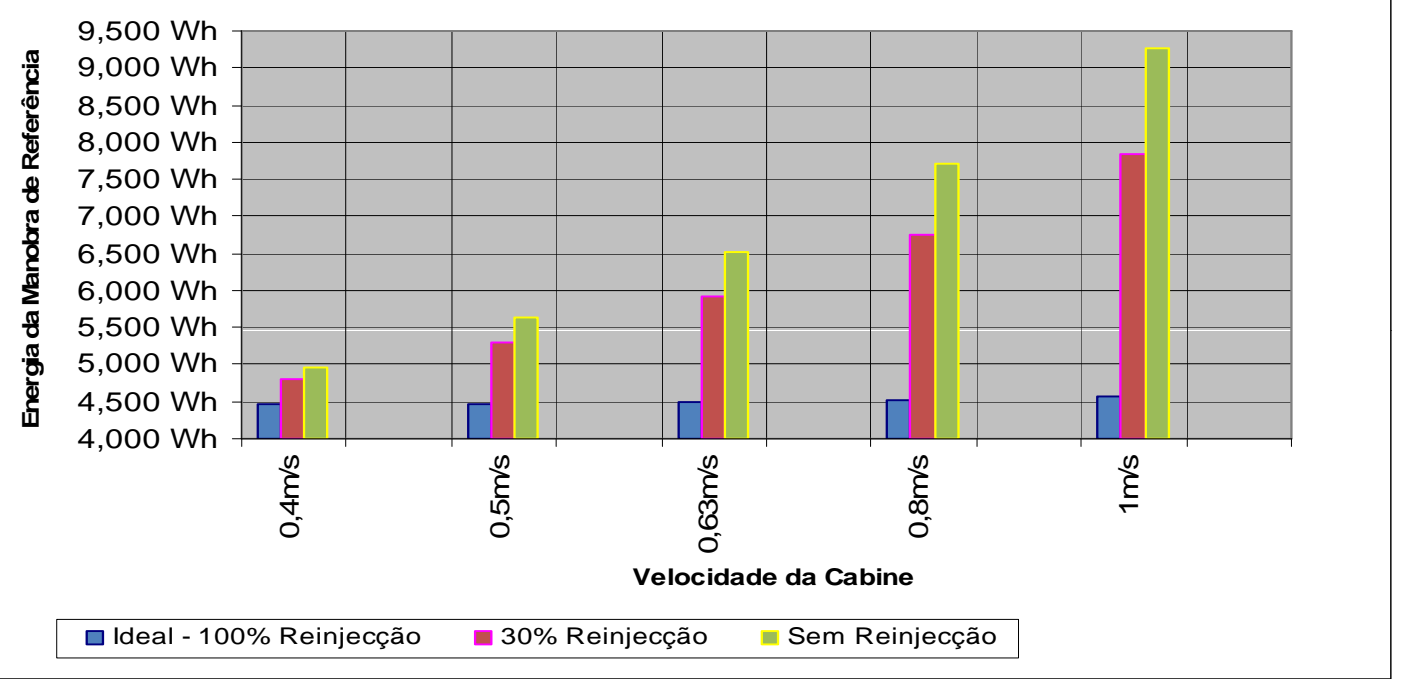

Figura 20 - Impacto da redução da velocidade do ascensor sobre o consumo energético

Em edifícios residenciais com curso reduzido, recomenda-se, por isso, a instalação de ascensores com velocidade reduzida. 
6 CONCLUSÕES

1. A concepção de ascensores eficientes em termos de energia contribuirá para um menor impacto ambiental;

2. Para se atingir o objectivo universal de utilização racional de energia (eléctrica) num edifício, não se deverá analisar apenas a eficiência energética, mas também o balanço energético. Assim, no caso dos ascensores, dever-se-á ter em conta, para além do período de operação, também o fabrico e a manutenção dos mesmos, o fornecimento de matérias-primas, bem como a sua reciclagem: a análise do ciclo de vida do produto.

3. Verificou-se que a temática da eficiência energética é ainda pouco explorada pela indústria de ascensores, seja através da incorporação nos ascensores das novas tecnologias já disponíveis em outras aplicações, seja através da divulgação de informação relevante em termos do desempenho energético dos equipamentos comercializados. Existem ainda muito poucos estudos realizados neste âmbito na Europa, com uma notável excepção da Suiça que tem vindo a patrocinar, através de uma organização estatal (a SAFE - Swiss Agency for Efficient Energy Use), vários estudos sobre a eficiência energética de ascensores;

4. Verificam-se diversas barreiras à adopção de ascensores eficientes em termos energéticos:

a) O Comprador e o utilizador do ascensor não têm interesses coincidentes: $\mathrm{Na}$ grande maioria das situações, o ascensor não é fornecido directamente ao cliente final, mas a uma empreiteiro geral que o incorpora no edifício. Este orienta-se fundamentalmente pelo preço de aquisição do ascensor e não pelos custos de energia eléctrica e de operação que este venha a provocar no futuro, que será sempre suportado pelo utilizador

b) Em edifícios existentes, ocorre uma grande resistência à incorporação de novos componentes que possam por em causa a operação e a disponibilidade dos ascensores existentes. Em novos edifícios é mais fácil incorporar as novas tecnologias.

Pelo que se recomenda uma sensibilização do cliente final bem como de projectistas.
5. Recomenda-se que o consumo energético dos ascensores seja considerado também no âmbito do Regulamento dos Sistemas Energéticos e de Climatização dos Edifícios (RSECE) - Decreto-Lei 79/2006 de 04 de Abril. Dessa forma existiria desde logo uma maior atenção na fase de projecto por parte dos projectistas relativamente à aplicação de ascensores eficientes energeticamente, para que pudessem ver aprovado o seu projecto.

\section{Bibliografia}

[1] ALMEIDA, Aníbal, PATRÃO, Carlos, FONSECA, Paula, MOURA, Pedro - Manual de boas práticas de eficiência energética. Lisboa, ISR - Departamento de Engenharia Electrotécnica e de Computadores Universidade de Coimbra e BCSD Portugal - Conselho Empresarial para o Desenvolvimento Sustentável, 2005.

[2] BARNEY, Gina - Elevator Traffic Handbook - Theory and Practice. Nova lorque, Spon Press, 2003. ISBN 0-41527476-I.

[3] BOLLA, Mario - Verbesserung der Energieeffizienz von Aufzügen und Förderanlagen durch Entwicklung eines Neuartigen Frequenzumformers - Jahresbericht 2007 Seftigen, Bundesamt für Energie, Suiça, 2007.

[4] CASTANHEIRA, Luís; BORGES GOUVEIA, Joaquim Energia, Ambiente e Desenvolvimento Sustentável. Porto, Spi - Sociedade Portuguesa de Inovação, 2004. ISBN 972-8589-45-X.

[5] CÓIAS, Vítor; FERNANDES, Susana - Reabilitação Energética dos Edifícios: Porquê? Oz - Diagnóstico Levantamento e Controlo de Qualidade em Estruturas e Fundações, Lda, 2006.

[6] KÜNTSCHER, Dietmar - Energiesparende Aufzugsysteme - Lift-Report no2 - Ano 32, 2006.

[7] FITZGERALD, A.; KINGSLEY, Charles; UMANS, Stephen Electric Machinery. Nova lorque, McGraw Hill, 2003. ISBN 0-07-123010-6.

[8] FRANCHI, C. - Acionamentos Eléctricos. Editora Érica, Ltda, 2007. ISBN 978-85-365-0149-9. 


\section{Bibliografia (Cont.)}

[9] GAMBOA, José - Ascensores e Elevadores. Lisboa, Rei dos Livros, 2005. ISBN 972-51-1007-2.

[10]JANOVSKY, Lumomír - Elevator Mechanical Design. 3a Edição. Mobile USA, Elevator World, Inc., 1999. ISBN 1886-536-26-0.

[11]MATIAS, José - Máquinas Eléctricas. 5ạ Edição. Lisboa, Didáctica Editora, 2005. ISBN 972-650-124-5.

[12]MEIRELES, Vitor - Circuitos Eléctricos. 3ạ Edição revista. Lisboa, Lidel - Edições Técnicas, Lda, 2005. ISBN 972-757386-X.

[13]NIPKOW, Jürg, SCHALCHER, Max - Energy consumption and efficiency potentials of lifts - Zurique. - SAFE - Swiss Agency for Efficient Energy Use, 2005.

[14]NIPKOW, Jürg - Elektrizitätsverbrauch und EinsparPotenziale bei Aufzügen - Bundesamt für Energie, 2005.

[15]PALMA, João - Accionamentos Electromecânicos de Velocidade Variável. 2ạ Edição. Lisboa, Fundação Calouste Gulbenkian - Serviço de Educação e Bolsas, 2008. ISBN 978-972-31-0839-2.

[16]PAIVA, J. Sucena - Redes de Energia Eléctrica - Uma Análise Sistémica. Lisboa, IST Press, 2005. ISBN 972-846934-9.

[17]RODRIGUES, José; MATIAS, José - Máquinas Eléctricas Transformadores. Lisboa, Didáctica Editora, 2005. ISBN 972-650-183-0.

\section{Directivas, Leis e Normas}

[1] DIRECTIVA 1995/16/CE do Parlamento Europeu e do Conselho de 29 de Junho de 1995 - Directiva Ascensores. Jornal Oficial das Comunidades Europeias.

[2] DIRECTIVA 2002/91/CE do Parlamento Europeu e do Conselho de 16 de Dezembro de 2002 - EPB - Energy Performance of Buildings - Desempenho Energético de Edifícios. Jornal Oficial das Comunidades Europeias.

[3] DIRECTIVA 2005/32/CE do Parlamento Europeu e do Conselho de 06 de Julho de 2005 - EuP - Energy Using Products - Requisitos de Concepção Ecológica dos Produtos que Consomem Energia. Jornal Oficial das Comunidades Europeias.

[4] DECRETO-LEI no 513/70 de 24 de Setembro.

[5] DECRETO-LEI no 295/98 de 22 de Setembro

[6] DECRETO-LEI no 78/2006 de 04 de Abril.

[7] DECRETO-LEI no 79/2006 de 04 de Abril.

[8] DECRETO-LEI no 80/2006 de 04 de Abril.

[9] DECRETO-LEI no 176/2008 de 26 de Agosto.

[10]NORMA PORTUGUESA NP 2058:1993 de Abril de 1993. Instituto Português da Qualidade.

[11]NORMA PORTUGUESA NP 4267:1994 de Maio de 1994 Instituto Português da Qualidade.

[12]NORMA PORTUGUESA NP 3661:1989 de Agosto 1989. Instituto Português da Qualidade.

[13]NORMA PORTUGUESA NP EN 81-1:2000 - Regras de Segurança para o Fabrico e Instalação de Elevadores Parte 1: Ascensores Eléctricos. Fevereiro de 2001. Instituto Português da Qualidade.

[14]NORMA PORTUGUESA NP EN 81-2:2000 - Regras de Segurança para o Fabrico e Instalação de Elevadores Parte 2: Ascensores Hidráulicos. Fevereiro de 2001. Instituto Português da Qualidade.

[15]NORMA SUIÇA SIA 380/4:2006 - Electricity in Buildings (2006), Swiss Society of Engineers and Architects (SIA).

[16]NORMA ALEMÃ VDI 4707:2009 - Ascensores - Eficiência Energética (2009), Verein Deutscher Ingenieure (VDI) 